\title{
INTERVALO HÍDRICO ÓTIMO EM DIFERENTES SISTEMAS DE PASTEJO E MANEJO DA PASTAGEM
}

TAIRONE PAIVA LEÃO

Dissertação apresentada à Escola Superior de

Agricultura "Luiz de Queiroz", Universidade de São Paulo, para obtenção do título de Mestre em Agronomia, Área de Concentração: Solos e Nutrição de Plantas.

PIRACICABA

Estado de São Paulo - Brasil

Dezembro - 2002 


\title{
INTERVALO HÍDRICO ÓTIMO EM DIFERENTES SISTEMAS DE PASTEJO E MANEJO DA PASTAGEM
}

\author{
TAIRONE PAIVA LEÃO \\ Engenheiro Agrônomo \\ Orientador: Prof. Dr. ÁLVARO PIRES DA SILVA
}

Dissertação apresentada à Escola Superior de

Agricultura "Luiz de Queiroz", Universidade de São Paulo, para obtenção do título de Mestre em Agronomia, Área de Concentração: Solos e Nutrição de Plantas.

PIRACICABA

Estado de São Paulo - Brasil

Dezembro - 2002 
Dados Internacionais de Catalogação na Publicação (CIP) DIVISÃO DE BIBLIOTECA E DOCUMENTAÇÃO - ESALQ/USP

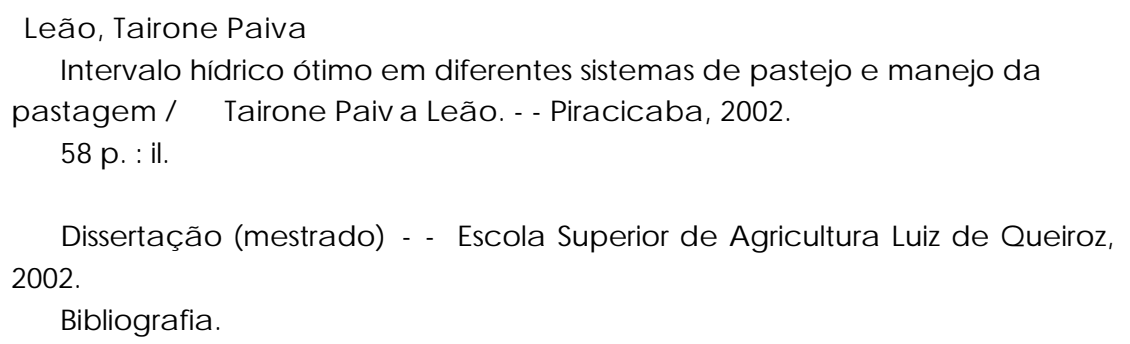

1. Capim brachiaria 2. Capim tanzânia 3 . Crescimento vegetal 4. Pastejo contínuo 5. Pastejo rotativo 6. Propriedade física do solo 7. Sistema de pastagem I. Título

CDD 631.43

"Permitida a cópia total ou parcial deste documento, desde que citada a fonte - $\mathrm{O}$ autor" 


\section{AGRADECIMENTOS}

Agradeço a todos que direta ou indiretamente colaboraram na realização deste trabalho. Em especial ao professor Álvaro Pires da Silva pela orientação e apoio sem os

quais este trabalho jamais teria se concretizado, e ao pesquisador Manuel Cláudio Motta Macedo pela valiosa colaboração. 


\section{SUMÁRIO}

Página

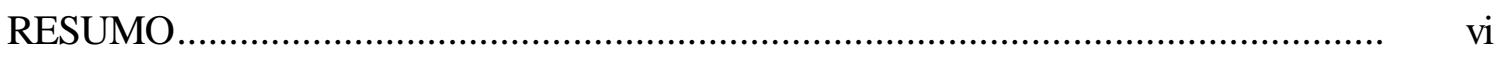

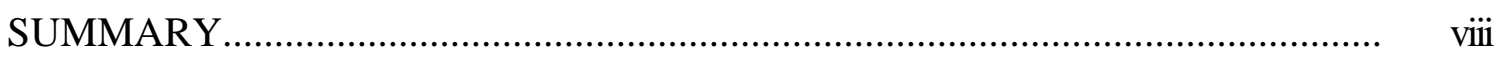

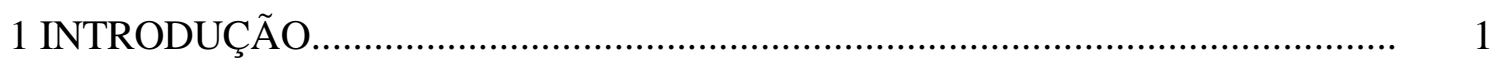



2.1 Propriedades físicas do solo que afetam diretamente o crescimento de plantas... 5

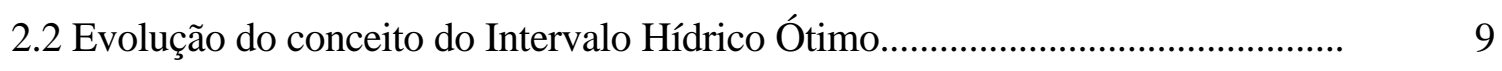

2.3 Qualidade física de solos sob pastagens....................................................... 14

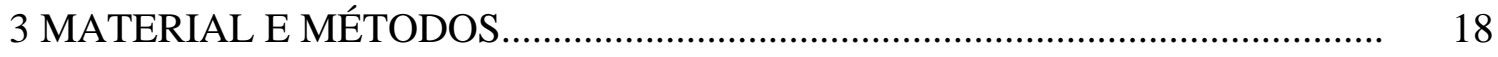

3.1 Caracterização da área experimental.......................................................... 18



3.3 Determinação do Intervalo Hídrico Ótimo......................................................... 20

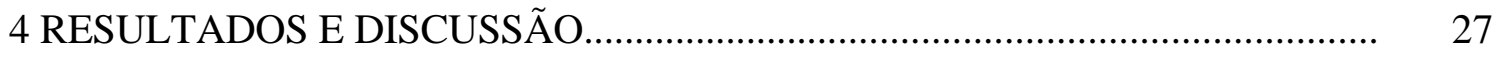

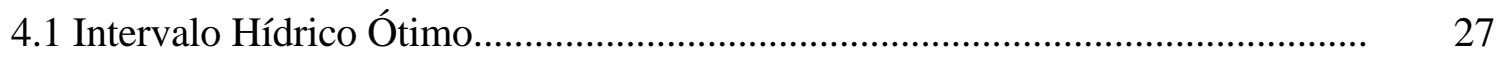

4.2 Intervalo Hídrico Ótimo entre tratamentos...................................................... 33

4.3 Distribuição espacial dos valores de densidade do solo....................................... 40

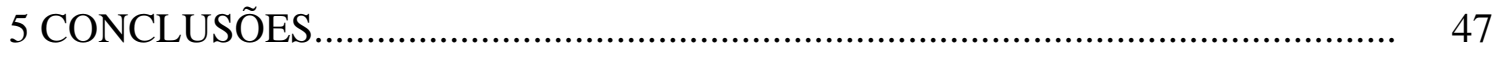


REFERÊNCIAS BIBLIOGRÁFICAS.................................................................. 48 


\title{
INTERVALO HÍDRICO ÓTIMO EM DIFERENTES SISTEMAS DE PASTEJO E MANEJO DA PASTAGEM
}

\author{
Autor: TAIRONE PAIVA LEÃO \\ Orientador: Prof. Dr. ÁLVARO PIRES DA SILVA
}

\section{RESUMO}

Foi desenvolvido um estudo com o objetivo de avaliar o efeito de diferentes sistemas de pastejo e manejo da pastagem sobre o Intervalo Hídrico Ótimo (IHO). A amostragem foi realizada na área experimental do Centro Nacional de Pesquisa de Gado de Corte, unidade da Empresa Brasileira de Pesquisa Agropecuária (Embrapa Gado de Corte). O solo estudado foi um Latossolo Vermelho Distrófico argiloso. Foram avaliados quatro piquetes, sendo dois no sistema de pastejo contínuo e dois no sistema de pastejo rotacionado, e uma área de cerrado $(\mathrm{CN})$. No sistema de pastejo contínuo, implementado com a espécie Brachiaria decumbens cv. Basilisk, foram retiradas 30 amostras por piquete, obedecendo a uma malha regular de $10 \times 10 \mathrm{~m}$, sendo que um dos piquetes não havia recebido adubação de manutenção (Cs) enquanto o outro havia recebido adubação bianual de manutenção $(\mathrm{Cc})$. No sistema de pastejo rotacionado, implementado com a espécie Panicum maximum cv. Tanzânia, foram retiradas 60 amostras por piquete, sendo 30 na psiç̧ão espacial touceira (t) e 30 na posição espacial entre touceiras (e), obedecendo a uma malha regular de $5 \times 10 \mathrm{~m}$. O diferencial entre os piquetes no sistema de pastejo rotacionado foi o resíduo pós pastejo. Em um dos piquetes o resíduo era de 2,0-2,5 Mg matéria seca total (MST) ha ${ }^{-1}$ (R1), enquanto no 
outro era de 3,0-3,5 Mg MST ha ${ }^{-1}$ (R2). No CN foram retiradas 30 amostras obedecendo a uma malha regular de $10 \times 10 \mathrm{~m}$. As amostras foram submetidas a um gradiente de tensão de água sendo posteriormente utilizadas nas determinações da densidade do solo $(D s)$, resistência à penetração de raízes $(\mathrm{RP})$ e umidade volumétrica $\left(\theta_{\mathrm{V}}\right)$. Em seguida, os resultados foram utilizados para o ajuste por regressão das curvas de resistência à penetração (CRP) e retenção de água do solo (CRA). Através da CRP e da CRA foi possível quantificar o IHO e a densidade crítica $(D s c)$, definida como o valor de $D s$ onde o IHO é igual a zero. O CN apresentou a melhor condição física do solo para o crescimento de plantas, sendo o IHO igual à água disponível. No sistema de pastejo contínuo estudado, a realização de adubação de manutenção não influenciou o $\mathrm{IHO}$, o que foi atribuído às taxas de lotação animal equivalentes nos dois piquetes. O sistema de pastejo rotacionado apresentou as piores condições físicas do solo para o crescimento vegetal, avaliadas pelo critério do IHO. Os maiores valores de $D s$ e menor IHO foram observados no R1e, o que foi atribuído às taxas de lotação elevadas aplicadas neste piquete. A posição espacial de amostragem (touceira e entre touceiras) não exerceu influência sobre o IHO no R2 enquanto no R1 o IHO foi muito menor entre as touceiras, o que pode ser atribuído ao hábito de crescimento cespitoso da espécie Panicum maximum cv. Tanzânia, deixando parte do solo descoberto e, portanto, sujeito à ação direta do pisoteio dos animais. 


\title{
LEAST LIMITING WATER RANGE IN DIFFERENT GRAZING SYSTEMS AND PASTURE MANAGEMENT STRATEGIES
}

\author{
Author: TAIRONE PAIVA LEÃO \\ Adviser: Prof. Dr. ÁLVARO PIRES DA SILVA
}

\section{SUMMARY}

A study was developed for evaluating the effect of different grazing systems and pasture management strategies on the Least Limiting Water Range (LLWR). The experimental site was located at the National Beef Cattle Research Center of Brazilian Agricultural Research Corporation (Embrapa Beef Cattle). The soil studied was a clay Oxisol (Typic Acrudox). Five sampling sites were selected: two under continuous grazing system, two under intensive short-duration grazing system, and one under native vegetation "cerrado" $(\mathrm{CN})$. Thirty soil cores were collected in each site under continuous grazing system, established with Brachiaria decumbens cv. Basilisk species. Sampling at continuous grazing sites was performed in a $10 \times 10 \mathrm{~m}$ regular grid. One of the continuos grazing sites had received biannual fertilization $(\mathrm{Cc})$ while the other was not fertilized (Cs). Sixty soil cores were collected in each site under intensive short-duration grazing system, established with Panicum maximum cv. Tanzânia species, with thirty cores in the spatial position under the plants (up) and thirty cores in the spatial position between the plants (bp). Sampling at intensive short-duration grazing sites was performed in a $5 \times 10 \mathrm{~m}$ regular grid. The difference between sites in intensive short- 
duration grazing system was the post-graze stubble. The post-graze stubble was 2,0-2,5 $\mathrm{Mg}$ total dry matter (TDM) ha ${ }^{-1}$ in one site (R1), and 3,0-3,5 $\mathrm{Mg} \mathrm{TDM}^{-1}$ in the other (R2). Thirty soil cores were collected in $\mathrm{CN}$, in a $10 \times 10 \mathrm{~m}$ regular grid. The cores were subjected to a soil water suction gradient, and then used for soil bulk density $(D b)$, soil penetration resistance $(\mathrm{PR})$ and volumetric water content $\left(\theta_{\mathrm{V}}\right)$ determinations. The data was used for developing soil resistance to penetration curve (SRP) and soil water retention curve (SWR) models doing regression fitting procedures. From SRP and SWR was possible to quantify the LLWR and the critical bulk density value $(D b c)$ identified as the $D b$ value where LLWR is null. The $\mathrm{CN}$ site had the best soil physical condition for plant growth with the LLWR equal to available water. The fertilization did not influenced the LLWR in the continuos grazing system under evaluation, as a consequence of the similar stocking rates at both sites. The intensive short-duration grazing system had the worst soil physical condition for plant growth, as evaluated by the LLWR. The highest $D b$ values and the lowest LLWR were found in R1bp, which may be a consequence of the high stocking rates observed at this site. The spatial sampling position (under the plants and between the plants) did not influenced the LLWR in the R2 site while in R1 the LLWR was much lower between plants. This result is a consequence of the cespitose growth habit of the Panicum maximum cv. Tanzânia species, which leaves part of the soil surface uncovered and subjected to a direct action of animal trampling. 


\section{INTRODUÇÃO}

As pastagens cultivadas estão concentradas no ecossistema Cerrados, com 49,5 milhões de hectares em uma área total de 208 milhões de hectares. Cerca de 50\% da produção de carne que abastece o Brasil é concentrada nesta região. Entretanto, a sustentabilidade deste sistema produtivo tem sido ameaçada pela degradação de solos e pastagens.

As características do sistema agropecuário brasileiro, onde solos marginais são destinados ao cultivo de pastagens, aliado ao emprego de espécies e cultivares inadequadas, favorece os processos de degradação do solo e perda da sustentabilidade do sistema.

$\mathrm{O}$ processo de degradação se inicia com um manejo animal inadequado, com lotações excessivas, o que ocasiona uma redução nos níveis de nutrientes do solo, que se não corrigida a tempo provoca a perda de vigor e produtividade da pastagem. Com a degradação da pastagem o sistema fica mais sujeito à invasão de plantas daninhas e ao ataque de insetos e doenças, causando um enfraquecimento ainda maior da pastagem e falhas na cobertura do solo. Com isto, tem início o processo de degradação do solo associado a compactação e degradação das propriedades físicas. A degradação das propriedades físicas compromete o crescimento vegetal. O ciclo têm continuidade até que as perdas na produção animal se tornam insustentáveis para manutenção do sistema e o produtor é obrigado a mudar de ramo ou até abandonar a atividade.

A relação entre propriedades físicas do solo e crescimento de pastagens será o objeto de estudo deste trabalho. De acordo com o efeito que exercem sobre o crescimento vegetal as propriedades físicas do solo são divididas em dois grupos:

a) Aquelas que afetam diretamente o crescimento vegetal, através de seu efeito 
sobre processos metabólicos e funções vitais das plantas, como: aeração, resistência do solo à penetração, características de retenção de água, e temperatura.

b) Aquelas que afetam indiretamente o crescimento vegetal, através de seu efeito sobre as propriedades que influem diretamente sobre o crescimento vegetal, como: agregação, estruturação, textura, densidade do solo, porosidade, condutividade hidráulica, etc.

A grande maioria dos estudos que trata da relação entre pastagens cultivadas e propriedades físicas do solo realiza a quantificação de propriedades que afetam direta ou indiretamente o crescimento vegetal, porém de forma independente, de modo que o estabelecimento de uma correlação com o crescimento de plantas se torna difícil.

O Intervalo Hídrico Ótimo (IHO) integra os efeitos da aeração, resistência do solo à penetração, e características de retenção de água em função de uma única variável; a densidade do solo. O IHO corresponde a faixa de umidade do solo em que o crescimento vegetal é menos limitado, abrangendo o conceito da água disponível, mas levando também em consideração as limitações causadas por uma elevada resistência do solo à penetração radicular e uma má aeração no ambiente do solo. Em solos bem estruturados, com valores moderados de densidade do solo, o IHO é igual à água disponível, tendo como limite superior a capacidade de campo e limite inferior o ponto de murcha permanente. À medida que o solo sofre degradação física, a umidade em que a aeração se torna deficiente pode substituir a capacidade de campo como limite superior do $\mathrm{IHO}$, e a umidade em que a resistência à penetração limita o crescimento de plantas pode substituir o ponto de murcha permanente como limite inferior. O IHO têm sido empregado como índice da qualidade física de solos cultivados com espécies florestais e culturas anuais, em diferentes sistemas de manejo, porém sua eficácia nunca foi testada em solos cultivados com pastagens. A hipótese deste estudo é que o IHO é influenciado pelo sistema de pastejo, contínuo ou rotacionado e, pelo manejo adotado em cada sistema de pastejo, ou seja, o emprego de adubação de manutenção no sistema de pastejo contínuo e o resíduo pós pastejo no sistema de pastejo rotacionado.

O objetivo geral do trabalho foi determinar o Intervalo Hídrico Ótimo (IHO) em 
um Latossolo Vermelho Distrófico sob sistema de pastejo contínuo implantado com a espécie Brachiaria decumbens cv. Basilisk com e sem adubação de manutenção e, sob sistema de pastejo rotacionado implantado com a espécie Panicum maximum cv. Tanzânia em dois níveis de resíduo pós pastejo, empregando-se como testemunha uma área sob cerradão subperenifólio nativo.

Os objetivos específicos foram avaliar: i) $\mathrm{O}$ efeito de diferentes sistemas de pastejo sobre o IHO; i) O efeito de diferentes estratégias de manejo, para cada sistema de pastejo sobre o IHO; iii) A influência das posições espaciais touceira e entre touceiras sobre o IHO no sistema de pastejo rotacionado. 


\section{REVISÃO DE LITERATURA}

A avaliação da qualidade física do solo tem sido baseada na quantificação de propriedades do solo de difícil aquisição em termos de análises laboratoriais, dispêndio de tempo e recursos, e de baixa correlação em termos práticos e aplicáveis ao manejo do solo. Dentre estas propriedades as mais freqüentemente determinadas são: densidade do solo, textura, agregação, estabilidade de agregados, distribuição de poros e características de retenção de água (Letey, 1985).

Na prática, ao se chegar a um conjunto de dados contendo todas estas variáveis, verificava-se a impossibilidade de integrar todas ou pelo menos algumas delas em um parâmetro que pudesse ser facilmente calculado, interpretado, e aplicado ao manejo dos solos. Em vista de tais dificuldades Silva et al. (1994) propuseram um modelo, considerando propriedades físicas do solo de fácil aquisição e que podem ser obtidas em prazo relativamente curto, e integrando-as em função de uma única variável; a densidade do solo. Este modelo foi denominado por Silva et al. (1994) de "Least Limiting Water Range", uma adaptação do termo "Non-limiting Water Range" proposto por Letey (1985). A designação "Least Limiting Water Range" foi traduzida para o português e empregada como Intervalo Hídrico Ótimo (IHO) por Tormena et al. (1998).

O conceito do IHO pode ser melhor compreendido levando-se em consideração a forma diferencial com que as propriedades físicas do solo atuam sobre o crescimento das plantas e caracterizam o ambiente no qual as raízes se desenvolvem. De acordo com Letey (1985), as propriedades físicas do solo que influenciam o crescimento de plantas podem ser subdivididas em dois grupos: aquelas que possuem efeito direto sobre o desenvolvimento das plantas, e as que afetam indiretamente o crescimento das plantas. 


\subsection{Propriedades físicas do solo que afetam diretamente o crescimento de plantas}

A composição do ar do solo é diferente da composição do ar presente na atmosfera. O nível de $\mathrm{CO}_{2}$ da atmosfera, em volume, é próximo a 0,03\% ao passo que no solo esta concentração chega a $0,2-1 \%$ nas camadas superficiais. $O$ ar presente no solo também possui menor conteúdo de $\mathrm{O}_{2}$, em torno de $20,3 \%$, quando comparado com os 20,99\% presentes na atmosfera. Os altos níveis de $\mathrm{CO}_{2}$ são resultantes do processo de respiração dos organismos viventes, o qual consome $\mathrm{O}_{2}$ liberando o $\mathrm{CO}_{2}$ como produto final. $\mathrm{O} \mathrm{O}_{2}$ é essencial para a atmosfera do solo. A respiração das raízes das plantas depende em grande parte do suprimento de $\mathrm{O}_{2}$ do ar do solo. A respiração fornece energia para diversos processos metabólicos, incluindo a absorção ativa de íons pelas raízes (Mengel \& Kirkby, 1982).

No que se refere à disponibilidade de oxigênio no ambiente radicular o fator preponderante não é a quantidade volumétrica de $\mathrm{O}_{2}$ presente e sim a taxa de difusão de oxigênio (TDO), ou seja, a capacidade do solo em permitir uma difusão adequada deste gás da atmosfera até as raízes consumidoras, bem como a liberação do $\mathrm{CO}_{2}$. Letey (1985) propõe uma TDO de $0,2 \mu \mathrm{g} \mathrm{cm}^{-2}$ como o mínimo requerido para um crescimento radicular adequado. Para fins práticos, considera-se o valor de porosidade de aeração (PA) de 10\%, ou seja, $10 \%$ da porosidade total do solo, livre de água, como o valor mínimo para garantia de uma TDO adequada para um desenvolvimento satisfatório dos vegetais (Betz et al., 1998; Grable \& Siemer, 1968; Hall et al., 1994; Mckenzie \& McBratney, 2001; Silva et al., 1994; Zou et al., 2000).

A temperatura do solo é um fator importante no crescimento e desenvolvimento vegetal. A temperatura do solo afeta a germinação de sementes, o desenvolvimento das raízes e da planta, a atividade de microorganismos, a difusão de solutos e dos gases, as reações químicas, e uma série de outros processos relevantes que ocorrem no ambiente do solo. Existem diversas publicações que abordam o efeito da temperatura sobre os

processos que ocorrem nos solos e plantas, dentre os quais pode-se citar Brady \& Weil (1999). O comportamento térmico do solo pode ser modelado através do emprego da Lei de Fourier (Reichardt, 1996; Tenge et al., 1998). 
Apesar de existirem evidências dos efeitos da temperatura sobre o crescimento vegetal, principalmente em regiões temperadas com invernos rigorosos, em regiões tropicais a temperatura do solo raramente é um fator limitante ao desenvolvimento das culturas (Sanchez, 1976).

Além da aeração e temperatura do solo, o crescimento, morfologia e profundidade atingida pelo sistema radicular num dado perfil são também diretamente afetados pela resistência mecânica do solo à penetração, ou simplesmente, resistência à penetração (RP) (Mengel \& Kirkby, 1982). Durante o desenvolvimento do sistema radicular as plantas precisam explorar a porosidade presente no solo ou forçar a abertura de novos poros, superando a resistência oferecida pela matriz do solo (Dexter, 1988). Consequentemente, quanto maior a resistência do solo à penetração maior a dificuldade encontrada pela planta em promover um crescimento adequado de suas raízes ao longo do perfil. Como discutido por Dexter (1988), o aumento da RP não apresenta efeitos significativos sobre o dispêndio de energia requerido pela planta para o crescimento radicular, no entanto, a taxa de elongação radicular é consideravelmente afetada pelo acréscimo na RP.

Para culturas anuais isto significa que o sistema radicular não apresentará um desenvolvimento pleno e, posteriormente, durante os estágios de crescimento vegetativo mais intenso, bem como durante a fase reprodutiva, o sistema radicular pode não ser capaz de suprir a demanda hídrica da cultura e explorar toda a habilidade de fornecimento de nutrientes do solo. Em casos severos, onde a RP atinge valores muito elevados, principalmente quando seus efeitos se concatenam com um déficit hídrico severo no solo, pode ocorrer a perda total da produção. Em culturas perenes a elevação da RP, decorrente da compactação, pode prejudicar a renovação e aprofundamento do sistema radicular, provocando prejuízos na absorção de água e nutrientes do solo, e consequentemente reduções na produção (Mazza et al., 1994).

Plantas crescendo em ambientes onde seu sistema radicular é exposto a condições adversas também apresentam redução no crescimento da parte aérea. Além dos efeitos sobre a absorção de água e nutrientes discutidos anteriormente, existem evidências experimentais que indicam que raízes crescendo em ambientes desfavoráveis 
enviam sinais inibitórios para as folhas. Dentre as hipóteses prováveis, supõe-se que estes sinais sejam de natureza bioquímica, liberados pelas raízes na corrente transpiratória, como por exemplo o ácido abcísico (ABA) (Hurley \& Rowarth, 1999; Ismail \& Davies, 1998; Passioura, 1991).

A quantificação da exata resistência oferecida por um solo ao crescimento de raízes de plantas ainda não pode ser obtida experimentalmente, pois existem diferentes mecanismos biológicos e físicos, por parte da planta, e do solo respectivamente, envolvidos no processo. Apesar disso, diversos estudos propõem correlações inversas entre o crescimento de raízes e a resistência do solo à penetração (Bengough \& MacKenzie, 1994; Merotto \& Mundstock, 1999; Pabin et al., 1998; Weaich et al., 1996). As metodologias empregadas nestes estudos são normalmente complexas, pois é necessário um controle rígido de outros fatores que possam vir a influenciar o crescimento radicular das plantas, tais como aeração, temperatura e fotoperíodo.

Dentro desta perspectiva, métodos que procuram simular a penetração de raízes no solo através do emprego de hastes metálicas, providas ou não de um cone na extremidade inferior, têm sido desenvolvidos. Segundo Bradford (1986), a penetrabilidade do solo é a facilidade com que um objeto pode ser empurrado ou conduzido através do solo. Aparatos desenvolvidos com esta finalidade recebem a denominação de penetrômetros. Atualmente, os penetrômetros mais empregados são dos tipos estáticos e dinâmicos. Penetrômetros estáticos consistem de uma agulha, com um cone na extremidade, ligada a um medidor da força ou pressão aplicada (Herrick \& Jones, 2002). O medidor é normalmente composto por uma célula de carga ou um anel dinamométrico ligado a um registrador analógico ou a um transdutor de pressão. A força exercida pelo operador é normalizada com a área basal do cone fornecendo um parâmetro chamado índice do cone, normalmente registrado em $\mathrm{kPa}$ ou $\mathrm{MPa}$. Penetrômetros dinâmicos são baseados no fornecimento de uma quantidade conhecida de energia cinética ao penetrômetro, o que faz com que o mesmo se mova uma determinada distância através do solo. Esta distância depende da energia cinética aplicada ao penetrômetro, da geometria do cone, e da resistência do solo à penetração (Herrick \& Jones, 2002; Stolf, 1991). 
A taxa de elongação das raízes é altamente correlacionada com a RP do solo onde se desenvolvem. No entanto, os mecanismos de atuação de raízes e penetrômetros são notadamente distintos (Passioura, 1991). Bengough \& Mullins (1990) apresentam uma compilação de resultados experimentais demonstrando que a resistência oferecida pelo solo a um penetrômetro pode ser de duas a oito vezes maior que aquela encontrada pelas raízes durante o crescimento. Em termos generalizados, assume-se o valor de 2 MPa (Materechera, et al., 1991; Silva et al., 1994; Taylor et al., 1966; Tormena et al., 1998) como limite à partir do qual a RP do solo afeta negativamente o crescimento de plantas, podendo causar reduções severas na produção ou mesmo morte de plantas.

O conteúdo de água do solo, ou mais precisamente o potencial em que a água se encontra no solo, exerce um efeito ainda mais crítico sobre o crescimento vegetal. Segundo Letey (1985), a água atua como uma "variável de equilíbrio", amenizando ou agravando os efeitos da temperatura, aeração e resistência do solo à penetração.

A densidade de fluxo de calor no solo é diretamente proporcional à condutividade térmica do solo, a qual, por sua vez é fortemente influenciada pela umidade, assim, quanto maior o conteúdo de água no solo, maior o fluxo de calor (Reichardt, 1996).

A porosidade de aeração ou porosidade livre de água (Libardi, 2000) é diretamente afetada pelo conteúdo de água no solo. Considerando-se a porosidade total como um valor fixo, da pode ser ocupada parte por água e parte por ar, e deste modo, quanto maior a fração da porosidade ocupada por água, menor será a ocupada pelo ar. Quando a porosidade de aeração é menor que $10 \%$, a taxa de fluxo de $\mathrm{O}_{2}$ em direção ao sistema radicular das plantas é severamente prejudicado, afetando assim os processos metabólicos e o crescimento da raiz.

O efeito do conteúdo de água sobre a resistência à penetração é descrito por Baver et al. (1972). Segundo estes autores, há um rápido aumento na resistência com o decréscimo na umidade, indicando que a resistência do solo aumenta à medida que as partículas são aproximadas durante o processo de secagem do solo.

Considerando que diferentes solos retêm diferentes conteúdos de água a um dado potencial, o conceito da tensão com que a água está retida é útil em definir os limites de 
disponibilidade de água no solo para as culturas. Teoricamente, logo após um episódio de chuva ou irrigação, estando o solo completamente saturado, a água estaria livre no

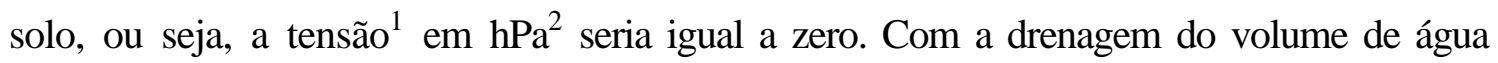
sujeito a ação do campo gravitacional, ou mais precisamente, quando o fluxo de drenagem se torna desprezível, o solo atinge o limite superior de disponibilidade de água para as plantas, normalmente conhecido como capacidade de campo (Reichardt, 1988). Para solos tropicais, assume-se que neste ponto a água no solo está retida a uma tensão de $100 \mathrm{hPa}$ (Haise et al., 1955). A água retida em tensões menores é tida como não disponível pelo fato de ser transitória, e mesmo que estivesse disponível esta água poderia causar prejuízos à planta, pela redução da porosidade de aeração. Partindo-se da capacidade de campo, a umidade no solo decresce gradualmente por meio da evaporação pela superfície e pela absorção pelas raízes das plantas. Com o decréscimo da umidade, há um aumento gradual da tensão, até que a energia com que a água é retida pelo solo supera a capacidade das plantas em absorver esta água, e a planta murcha permanentemente. Nesta situação o solo se encontra no ponto de murcha permanente, o qual possui boa correlação com a tensão de água no solo de $15000 \mathrm{hPa}$ (Haise et al., 1955; Richards \& Weaver, 1944).

A água retida entre a capacidade de campo e o ponto de murcha permanente é conhecida como água disponível às plantas ou, simplesmente, água disponível (AD). $\mathrm{O}$ conceito da $\mathrm{AD}$ é de fundamental importância para a compreensão do conceito do $\mathrm{IHO}$ que será abordado em detalhe posteriormente.

Deste modo, define-se como propriedades que afetam dretamente o crescimento de plantas: aeração, temperatura, resistência do solo à penetração e umidade, ou mais precisamente potencial da água no solo (Letey, 1985; Silva et al., 1994).

\subsection{Evolução do conceito do Intervalo Hídrico Ótimo}

A busca por um índice da qualidade física do solo que integrasse os efeitos da

\footnotetext{
${ }^{1}$ Tensão de água no solo é equivalente ao módulo do potencial mátrico.

${ }^{2} \mathrm{~A}$ unidade $\mathrm{hPa}$ é numericamente equivalente à unidade centímetros de coluna de água.
} 
tensão com que a água é retida pelo solo, resistência à penetração e aeração não é recente. Eavis (1972) desenvolveu um estudo no qual avaliou o crescimento radicular de plântulas de ervilha (Pisum sativum L.) em um solo franco arenoso em três densidades do solo e seis tensões. O principal mérito deste estudo foi demonstrar a forma diferencial com que as propriedades físicas do solo atuam sobre o crescimento de plantas, a partir da variação da densidade do solo e umidade. Em valores mais baixos de densidade a principal limitação ao crescimento nas menores tensões de água (solo úmido) foi a aeração enquanto que em tensões mais elevadas (solo seco) foi o déficit hídrico. Por outro lado, com a elevação da densidade do solo as limitações referentes à resistência à penetração foram atuantes, a princípio apenas tensões mais elevadas, e nas densidades mais altas também nas tensões menores.

Phene \& Beale (1976) definiram uma faixa ideal de tensão de água para o crescimento de plantas no solo considerando a curva de retenção de água no solo. Neste estudo, a irrigação de alta frequiência era aplicada de modo a manter a tensão de água dentro da faixa ideal para o crescimento radicular. Em maiores valores de umidade do solo o crescimento radicular foi limitado pela aeração, correspondendo a um valor crítico de tensão de água a partir do qual a TDO era menor que $0,4 \mu \mathrm{g} \mathrm{cm}^{-2} \mathrm{~min}^{-1} \mathrm{e}$ em menores valores de umidade do solo a um valor crítico de tensão a partir do qual a resistência do solo à penetração superava os $2 \mathrm{MPa}$. Os autores observaram que, à medida que a densidade do solo aumentou, a faixa ideal de tensão de água para o crescimento de plantas diminuiu.

Os estudos de Eavis (1972) e Phene \& Beale (1976) definiram os fundamentos do que viria a ser o IHO, no entanto, a primeira descrição qualitativa do Intervalo Hídrico Ótimo foi realizada por Letey (1985). Segundo Letey, o intervalo hídrico não limitante (Non-limiting water range), termo que posteriormente foi adaptado para IHO, pode ser afetado pela aeração e/ou resistência mecânica, particularmente em solos mal estruturados e com valores elevados de densidade. O IHO complementa o conceito da $\mathrm{AD}$ incluindo limitações ao crescimento de plantas, até então, ignoradas a avaliadas de forma independente do conceito da AD. Em um solo bem estruturado, com valores moderados de densidade, a faixa de umidade na qual as plantas encontram condições 
ótimas para o crescimento é definida pelas umidades na capacidade de campo $\left(\theta_{\mathrm{CC}}\right)$, e no ponto de murcha permanente $\left(\boldsymbol{\theta}_{\mathrm{PMP}}\right)$. Com a degradação estrutural do solo e o aumento da densidade, ocorre uma redução da porosidade total. Isto pode fazer com que ocorram limitações causadas por uma PA inferior a $10 \%$ em umidades iguais ou menores que aquela correspondente a $\theta_{\mathrm{CC}}$. Por outro lado, sabendo-se que a RP é função não apenas da umidade do solo mas também da densidade, com a compactação podem ocorrer valores de RP limitantes ao crescimento de plantas em umidades do solo maiores que a $\theta_{\mathrm{PMP}}$. Neste caso o IHO seria definido pela PA no limite superior e pela RP no limite inferior.

A caracterização e quantificação do IHO incluindo a densidade do solo como variável de monitoramento foi concretizada por Silva et al. (1994). Neste trabalho é realizada uma descrição detalhada do IHO, incluindo aspectos estatísticos e metodológicos. Silva et al. (1994) estabeleceram a curva característica de retenção de água no solo como função de duas variáveis independentes; tensão de água e densidade do solo $(D s)$, a RP por sua vez foi estabelecida como função da $D s$ e da umidade volumétrica do solo $(\theta \mathrm{v})$. Como a $\theta_{\mathrm{CC}}$ foi estabelecida em $100 \mathrm{hPa}$ e a $\theta_{\mathrm{PMP}}$ em 15000 $\mathrm{hPa}$, a $\mathrm{AD}$ pôde ser definida como função da $D s$. Os autores estabeleceram um valor de $\mathrm{RP}$ de $2 \mathrm{MPa}$ como limitante ao crescimento radicular. Isolando-se a $\theta_{\mathrm{V}}$ no modelo de $\mathrm{RP}$, definiu-se a umidade em que a RP supera o valor crítico $\left(\boldsymbol{\theta}_{\mathrm{RP}}\right)$, fixado nesse estudo em $2 \mathrm{MPa}$, como função apenas da $D s$. Deste modo o IHO foi quantificado como função da $D s$ estabelecendo-se um novo índice da qualidade física do solo. O IHO quantificado por Silva et al. (1994) segue a conceituação de Letey (1985), uma vez que o limite superior pode ser definido pela umidade em que a porosidade de aeração é inferior a $10 \%\left(\theta_{\mathrm{PA}}\right)$ ou pela $\theta_{\mathrm{CC}}$, e o limite inferior pode ser definido pela $\theta_{\mathrm{RP}}$ ou pela $\theta_{\mathrm{PMP}}$. Silva e seus colaboradores observaram ainda que $\theta_{P A}$ e $\theta_{R P}$ foram mais severamente afetadas pela $D s$ do que $\theta_{\mathrm{CC}}$ e $\theta_{\mathrm{PMP}}$, indicando que o IHO é um parâmetro mais sensível à mudanças estruturais no solo que a AD. A metodologia proposta por Silva et al. (1994) foi adotada na realização do presente estudo, e portanto, será abordada com detalhe posteriormente. 
O emprego do IHO como índice da qualidade física do solo tem se difundido nos últimos anos. Betz et al. (1998) empregaram o IHO na avaliação do impacto do cultivo e tráfego sobre o ambiente radicular, em duas profundidades. Eles concluíram que o limite superior do IHO foi definido pela $\theta_{\mathrm{CC}}$ no tratamento onde não havia tráfego nas entrelinhas, com cultivo anual, enquanto que a $\theta_{\mathrm{PA}}$ foi o limite superior no tratamento em que foi realizado plantio direto sem tráfego nas entrelinhas, na camada compactada pelo cultivo, e nos tratamentos onde houve tráfego nas entrelinhas. A $\theta_{\mathrm{RP}}$ atuou como limite inferior do IHO na camada compactada e nos tratamentos onde não foi realizado cultivo, enquanto que o $\theta_{\mathrm{PMP}}$ foi o limite inferior do IHO nos demais tratamentos.

A qualidade física do solo em um sistema de cultivo conservacionista foi avaliada por Carter et al. (1999) através de propriedades hidráulicas do solo, compressão uniaxial e pelo IHO. O IHO foi muito menor no sistema conservacionista do que no sistema convencional. Isto se deveu ao fato da RP superar os $2 \mathrm{MPa}$ em maiores conteúdos de água no sistema de semeadura direta que no sistema de cultivo convencional, conseqüência dos maiores valores de $D s$ na ausência de cultivo. Neste estudo também foi empregada a razão IHO:AD para caracterizar o ambiente físicohídrico do solo, sendo este índice muito menor no sistema conservacionista.

O IHO foi citado por Schoenholtz et al. (2000), Silva et al. (2002a) e Souza (2002) como indicador da qualidade física de solos florestais. Apesar da aplicabilidade do conceito Schoenholtz et al. (2000) ressaltam para possíveis restrições causadas pelo alto nível de variabilidade, tanto horizontal quanto vertical, comum em solos florestais. Zou et al. (2000) testaram o IHO como indicador da qualidade física de solos florestais. Foram empregados quatro tipos de solos com classes texturais contrastantes. ARP de 3 $\mathrm{MPa}$ foi adotada como valor à partir do qual o crescimento radicular sofre maiores limitações. Silva et al. (1994) apesar de proporem o valor de $2 \mathrm{MPa}$ como limite da RP para o crescimento de plantas também testaram a influência dos valores 3 , 4 e $5 \mathrm{MPa}$ no IHO. Zou et al. (2000) verificaram aumento do IHO com o aumento na Ds em alguns tratamentos, o que se deveu à redução da macroporosidade, causando um aumento nos poros de tamanho médio, e a uma menor taxa de incremento da RP com o aumento da Ds. Para estes autores, o IHO pode atuar como indicador do impacto das práticas de 
manejo sobre as condições físicas do solo. Caso o IHO não seja aumentado ou reduzido têm-se um indicativo de um manejo adequado das propriedades físicas do solo. Uma redução do IHO pode significar redução da produtividade e que o manejo destinado ao solo pode não ser sustentável.

Sharma \& Bhushan (2001) observaram que a adição de biomassa ao solo provocou aumento na $\theta_{\mathrm{PA}}$ e decréscimo na $\theta_{\mathrm{RP}}$, implicando em aumento do IHO. O IHO e a razão IHO:AD foram de 1,7 a 3,5 e de 1,7 a 3,1 vezes maiores, respectivamente, nos tratamentos onde foi aplicada biomassa em relação a testemunha.

No Brasil a primeira quantificação do IHO foi realizada por Tormena et al. (1998) em um Latossolo muito argiloso. O IHO se mostrou mais sensível à variações na estrutura do solo que a $\mathrm{AD}$, comportamento também observado em outras classes de solos (Betz, et al. 1998; Silva et al. 1994; Zou et al. 2000). $\theta_{\mathrm{RP}}$ e $\theta_{\mathrm{PA}}$ foram fortemente influenciadas pela densidade do solo. A $\theta_{\mathrm{RP}}$ representou o limite inferior do IHO em $85 \%$ das amostras e a $\theta_{\mathrm{CC}}$ representou o limite superior em $97 \%$ das amostras. Tormena et al. (1999) avaliaram o efeito de sistemas de cultivo sobre o IHO em um Oxissolo brasileiro. Eles observaram um forte efeito da Ds sobre o IHO nos dois sistemas estudados, sendo o efeito mais pronunciado no sistema de semeadura direta, onde a $\theta_{\mathrm{RP}}$ representou o limite inferior do $\mathrm{IHO}$ em $89 \%$ das amostras, substituindo a $\theta_{\mathrm{PMP}}$ em valores de $D s \quad 1,06 \mathrm{~g} \mathrm{~cm}^{-3}$. Por outro lado, no sistema de cultivo convencional, a $\theta_{\mathrm{RP}}$ representou o limite inferior em $46 \%$ das amostras, substituindo a $\theta_{\text {PMP }}$ em valores de $D s$ $1,13 \mathrm{~g} \mathrm{~cm}^{-3}$.

Apesar das descrições quantitativas e qualitativas do IHO citadas anteriormente, existe uma demanda por estudos que correlacionem o IHO com o crescimento de plantas, de modo que este índice possa ser validado como indicador da qualidade física do solo (Lal, 2000). Silva \& Kay (1996) avaliaram o efeito do IHO sobre o crescimento de plantas de milho, relacionando crescimento da cultura com a proporção do número total de medidas de umidade do solo que se localizaram fora dos limites do IHO $\left(p_{\text {out }}\right)$. O crescimento foliar do milho declinou linearmente com o $p_{\text {out }}$ e aumentou de forma não linear quando relacionado com o IHO. 
A praticidade do conceito do IHO têm levado pesquisadores a buscar formas de estimá-lo de maneira mais rápida e mais simples do ponto de vista operacional, através de propriedades físicas do solo determinadas em procedimentos de rotina. Este processo consiste na obtenção de funções de pedotransferência (Bouma, 1989; van den Berg et al., 1997). A relação funcional entre IHO e propriedades do solo pode ser descrita através de funções de pedotransferência desenvolvidas para modelar as curvas de retenção de água e de resistência à penetração do solo. Para uma dada combinação de argila, carbono orgânico e $D s$ o IHO pode ser estimado em diferentes valores críticos associados à PA, RP e tensão de água no solo (Silva \& Kay, 1997a). McKenzie \& McBratney (2001) estimaram o IHO através de medidas de resistência ao cisalhamento e umidade do solo, ressaltando as restrições à aplicabilidade de valores críticos de parâmetros estruturais do solo na presença de macroporos. Groenevelt et al. (2001) propuseram uma metodologia para tornar mais flexível o cálculo da faixa de água no solo ideal para o crescimento de plantas, em relação ao IHO ou AD. Esta metodologia, denominada de água disponível integral, é baseada em funções balanceadas, o que segundo os autores, evita o emprego de limites críticos como por exemplo $\theta_{\mathrm{PA}}$ ou $\theta_{\mathrm{PMP}}$.

O IHO têm se mostrado um bom índice da qualidade física de solos empregados no cultivo de espécies florestais e culturas anuais, em diferentes sistemas de manejo. No entanto seu desempenho não foi avaliado em solos sob pastagens.

\subsection{Qualidade física de solos sob pastagens}

No Brasil poucos estudos têm sido realizados sobre o impacto de sistemas de pastejo sobre as propriedades físicas do solo, apesar do interesse sobre o tema ter crescido nos últimos anos (Silva et al., 1997a). O pouco interesse por aspectos físicos de solos cultivados com pastagens se deve às próprias características do sistema de exploração agropecuária no Brasil, onde solos de maior aptidão agrícola são ocupados pelas lavouras anuais de grãos ou, as de grande valor industrial para a produção de óleo, fibras, resinas, etc., restando os solos marginais para exploração pecuária (Macedo, 2001), nos quais são empregados poucos recursos e em geral não são tomadas 
precauções no que se refere ao manejo adequado do solo.

A degradação de solos cultivados com pastagens é um processo contínuo de alterações, que tem início com a perda de vigor e produtividade da pastagem. A degradação física do solo é um dos últimos estágios deste processo, no qual, medidas mais drásticas e onerosas são necessárias para recuperação da capacidade produtiva do sistema. Macedo (2001) cita ainda como fatores mais importantes relacionados à degradação das pastagens o manejo animal inadequado e a falta de reposição de nutrientes. A lotação animal excessiva sem os ajustes para uma adequada capacidade de suporte, e a ausência de adubação de manutenção têm sido os aceleradores do processo de degradação.

Ao longo do tempo o pisoteio em toda superfície, e às vezes repetidamente no mesmo local, pode promover drásticas alterações nas condições do solo para o crescimento do sistema radicular. A extensão e a natureza desses efeitos são determinados pela taxa de pisoteio, pelo tipo de solo, e principalmente pela umidade do solo. O pastejo realizado em condições elevadas de umidade do solo maximiza a degradação física do solo, prejudicando o crescimento de plantas (Betteridge et al., 1999; Silva et al., 1997a).

A consequiência primária do pisoteio excessivo em umidades inadequadas é a compactação do solo definida por Baver et al. (1972, p.107) como "o aumento na densidade do solo como resultado de cargas ou pressões aplicadas".

A maioria dos estudos à respeito da parte física dos solos cultivados com pastagens são baseados em propriedades que afetam direta ou indiretamente o crescimento vegetal, como: Ds (Abaye et al., 1997; Bell et al., 1997; Davies et al., 1989; Harrison et al., 1994; Krzic et al., 1999; Mapfumo et al., 1998; Mead \& Chan, 1992; Nie et al., 2001), RP (Imhoff et al., 2000a; Imhoff et al., 2000b; Krzic et al., 1999; Mead \& Chan, 1992; Williams \& Kalmbacher, 1996), condutividade hidráulica (Bell et al., 1997; Betteridge et al., 1999; Francis et al., 1999; Harrison et al., 1994; Krzic et al., 1999; Mead \& Chan, 1992), porosidade (Davies et al., 1989; Francis et al., 1999; Hart et al., 1988; Mead \& Chan, 1992), resistência tênsil (Proffitt et al., 1995a), argila dispersa (Muller et al., 2001), agregação (Bell et al., 1997; Francis et al., 1999; Mead \& Chan, 
1992), e características de retenção de água (Bell et al., 1997; Hart et al., 1988; Mapfumo et al., 2000; Williams \& Kalmbacher, 1996), no entanto, na maioria dos casos, considerando as propriedades físicas individualmente, e em nenhum deles realizando a quantificação do IHO.

A compactação dos solos sob pastagens é complexa e têm sido objeto de menor número de estudos que em solos sob outros tipos de culturas. Uma das principais questões se refere a real capacidade de recuperação do solo decorrente das interações entre o solo e o sistema radicular de espécies utilizadas como pastagens, bem como o tempo de pousio adequado para que este processo ocorra. Stephenson \& Veigel (1987) estudando o efeito do pisoteio de bovinos em pastagens de Medicago sativa e Bromus biebersteinii relataram um período de 16 meses para que a densidade do solo dos piquetes tivesse uma recuperação de $92 \%$ com relação à testemunha. Por outro lado, Mead \& Chan (1992) observaram um processo de recompactação em piquetes não pastejados. Decaëns et al. (1999) comentam que os principais fatores influenciando as propriedades físicas do solo foram o tipo e a idade da pastagem, o que pode ser devido a efeitos específicos da planta, índice de área foliar, qualidade e quantidade de liteira produzida, e efeitos cumulativos do pisoteio animal os quais podem diferir de acordo com o histórico e natureza da pastagem.

Outro ponto a ser esclarecido se refere ao valor limite de RP a partir do qual o crescimento de gramíneas forrageiras é severamente limitado. A susceptibilidade da planta à valores elevados de RP é função de variáveis da planta, como fenologia e vigor. De maneira geral, o valor de $2 \mathrm{MPa}$ é aceito como crítico para a maioria das espécies cultivadas (Materechera, et al., 1991; Silva et al., 1994; Taylor et al., 1966; Tormena et al., 1998). Para espécies florestais o valor adotado têm sido o de $3 \mathrm{MPa}$ (Sands et al., 1979; Zou et al., 2000). Para pastagens tem sido adotado o valor de RP de 2,5 MPa como limitante ao crescimento das plantas (Imhoff et al., 2000a) porém, são necessários mais estudos relacionando aspectos fisiológicos, morfológicos e produtivos das pastagens ao aumento da RP do solo.

O efeito da posição relativa às plantas e da área entre plantas nas propriedades físicas do solo também têm sido objeto de estudo em culturas anuais e pastagens. 
Correchel (1998) e Silva et al. (1997b) encontraram menores valores de Ds nas linhas das plantas na cultura do milho que nas entrelinhas, o que pode ser atribuído ao tráfego de máquinas e implementos e ao menor volume de raízes presentes em tal posição. Imhoff et al. (2000a) estudaram o efeito das posições espaciais: touceira e entre touceiras, em propriedades físicas de pastagens cultivadas com capim-elefante (Penisetum purpureum Schum.), em sistema de pastejo rotacionado intensivo. Tanto a RP quanto a $D s$ foram menores na posição touceira, o que foi atribuído à maior produção de biomassa vegetal nesta posição e ao maior pisoteio dos animais entre as touceiras. 


\section{MATERIAL E MÉTODOS}

\subsection{Caracterização da área experimental}

O estudo foi desenvolvido no Centro Nacional de Pesquisa de Gado de Corte, unidade da Empresa Brasileira de Pesquisa Agropecuária (Embrapa Gado de Corte) localizada em Campo Grande, Mato Grosso do Sul, com coordenadas geográficas $20^{\circ}$ 26' 48" de latitude sul e 54 43' 19" de longitude oeste, e a uma altitude de $530 \mathrm{~m}$. A área, segundo a classificação de Köppen, situa-se na faixa de transição entre o clima (Cfa) mesotérmico úmido sem estiagem, em que a temperatura média do mês mais seco é superior a $22^{\circ} \mathrm{C}$, apresentando o mês mais seco mais de $30 \mathrm{~mm}$ de chuvas e o clima (Aw), tropical úmido, com estação chuvosa no verão e seca no inverno. A precipitação

pluviométrica anual é em torno de $1500 \mathrm{~mm}$, sendo novembro, dezembro, janeiro e fevereiro os meses mais chuvosos, enquanto junho, julho e agosto são os meses mais secos. A temperatura média anual oscila entre 19 e $25^{\circ} \mathrm{C}$, com as máximas ocorrendo no período compreendido entre os meses de outubro e março e as mínimas entre os meses de maio e julho (Embrapa, 1979).

O solo utilizado foi um Latossolo Vermelho Distrófico (Embrapa, 1999) com teores médios de $399 \mathrm{~g} \mathrm{~kg}^{-1}$ de argila, $66 \mathrm{~g} \mathrm{~kg}^{-1}$ de silte e $535 \mathrm{~g} \mathrm{~kg}^{-1}$ de areia, determinados através do método do densímetro (Gee \& Bauder, 1986), sendo definido quanto à classe textural como argiloso. As amostragens foram realizadas em quatro piquetes, onde estão implementados experimentos da Embrapa Gado de Corte, e em uma área de cerradão subperenifólio nativo ou, resumidamente, cerrado (Pivello \& Coutinho, 1996), tendo sido definidos os seguintes tratamentos:

$>$ Dois piquetes com área total de 0,18 ha cada $(56,25$ x 33,33 m) estabelecidos 
com a espécie forrageira Panicum maximum cv. Tanzânia (Figura 1). Os piquetes são submetidos ao sistema de pastejo rotativo, com 7 dias de pastejo e 35 dias de descanso. Estes piquetes são parte de um experimento implementado em 1999, tendo sido concluídos três ciclos pecuários. Os animais utilizados são bezerros desmamados cruzados (Nelore x Angus), que iniciam o pastejo em maio e permanecem no experimento até o abate, que varia de 18 a 24 meses de idade, sendo portanto o tempo de pastejo de 12 a 18 meses. O experimento foi projetado para manter uma saturação por bases na faixa de 45-50\% na camada de 0-20 cm de profundidade, teores de fósforo disponível em Mehlich-1 (Nelson et al., 1953) na faixa de 4-8 $\mathrm{mg} \mathrm{dm}^{-3}$, e potássio na faixa de $60-80 \mathrm{mg} \mathrm{dm}^{-3}$. A adubação nitrogenada anual é de 100 $\mathrm{kg} \mathrm{ha}{ }^{-1} \mathrm{ano}^{-1}$, aplicados em duas etapas: $50 \mathrm{~kg}$ em nov./dez. e $50 \mathrm{~kg}$ em jan./fev., alternado como fonte de $\mathrm{N}$ uréia e sulfato de amônio, logo após a saída dos animais do piquete pastejado. O diferencial entre os piquetes está no nível de resíduo pós pastejo, que neste caso é função direta da lotação animal. Em um dos piquetes o resíduo é de 2,0-2,5 Mg de matéria seca total (MST) $\mathrm{ha}^{-1}$, sendo este piquete designado (R1) e no outro piquete o resíduo pós pastejo é de 3,0-3,5 $\mathrm{Mg} \mathrm{MST} \mathrm{ha}^{-1}$, sendo designado (R2).

Dois piquetes com área total de 0,7 ha cada $(50$ x $140 \mathrm{~m})$ estabelecidos com a espécie forrageira Brachiaria decumbens cv. Basilisk (Figura 1). O pastejo é realizado com lotação contínua, sendo utilizados dois animais por piquete (fêmeas aneloradas). Os animais entram nos piquetes no mês de maio e são retirados após um ano. Animais adicionais são colocados ou retirados com o objetivo de manter a disponibilidade de forragem em 3,0 $\mathrm{Mg} \mathrm{MST} \mathrm{ha}^{-1}$. Os piquetes foram implementados à partir da recuperação de uma pastagem degradada em novembro de 1993, com calagem (2,5 $\mathrm{Mg} \mathrm{ha}^{-1}$ ) e adubação (350 $\mathrm{kg} \mathrm{ha}^{-1}$ da formulação comercial 0-20-20). Destes dois piquetes um não recebeu adubação de manutenção, sendo designado (Cs), enquanto o outro recebeu adubação bianual (400 $\mathrm{kg} \mathrm{ha}^{-1}$ da formulação comercial 0-20-20 
aplicada à lanço), calagem superficial em $1998\left(2 \mathrm{Mg}^{-1}\right)$, e gessagem (500 $\mathrm{kg} \mathrm{ha}^{-1}$ ) sendo designado $(\mathrm{Cc})$.

Nos piquetes com pastejo contínuo a lotação média anual foi de 1,68 UA ha ${ }^{-1}$ no Cc e de 1,53 UA ha ${ }^{-1}$ no Cs. Nos piquetes com pastejo rotacionado a lotação média de três ciclos foi de 4,8 e 4,12 $\mathrm{UA} \mathrm{ha}^{-1}$ nos tratamentos R1 e R2, respectivamente, para o período chuvoso, e 2,26 UA ha ${ }^{-1}$ (com suplementação) para os dois resíduos no período seco. Segundo Macedo ${ }^{3}$, no pastejo rotacionado, em nove meses do ano (exceto junho, julho e agosto) $90 \%$ da matéria seca total (MST) do Panicum maximum cv. Tanzânia é composta de matéria seca verde (MSV).

\subsection{Amostragem}

Foram retirados 30 anéis volumétricos de $5 \mathrm{~cm}$ de altura por $5 \mathrm{~cm}$ de diâmetro interno, por piquete nos tratamentos $\mathrm{Cs}$ e $\mathrm{Cc}$, obedecendo a uma malha regular de $10 \mathrm{x}$ $10 \mathrm{~m}$. Nos tratamentos R1 e R2 foram coletados 60 anéis por piquete obedecendo a uma malha regular de $5 \times 10$ m, sendo 30 anéis coletados na posição espacial touceira (R1t) e (R2t), e 30 anéis na posição espacial entre touceiras (R1e) e (R2e) (Figura 1). Nas amostras coletadas na posição espacial touceira, a biomassa da parte aérea das plantas foi retirada, sem alterar a condição do solo. A amostragem foi realizada no solo, imediatamente ao lado dos colmos cortados rentes ao chão. $\mathrm{Na}$ área de cerrado nativo (CN) foram retiradas 30 amostras obedecendo a uma malha regular de $10 \times 10 \mathrm{~m}$.

Foram retiradas 210 amostras de solo indeformado, na forma de anéis volumétricos, na camada de 0-10 cm, e mais uma amostra composta, deformada, por tratamento para caracterização granulométrica.

\subsection{Determinação do Intervalo Hídrico Ótimo}

No laboratório as amostras indeformadas foram saturadas, por redução lenta e

\footnotetext{
${ }^{3}$ MACEDO, M.C.M. Comunicação pessoal, 2002.
} 
gradual da tensão de água em mesas de tensão adaptadas de Topp \& Zebchuk (1979). A curva de retenção de água no solo foi determinada seguindo o procedimento descrito por Silva et al. (1994). As amostras foram divididas em 10 grupos de 21, sendo 3 amostras de cada tratamento por grupo. Cada grupo de amostras foi submetido a uma das seguintes tensões: 20, 40, 60, 80 e $100 \mathrm{hPa}$ em mesas de tensão (Topp \& Zebchuk, 1979); e 300, 500, 700, 1000 e 15000 hPa em câmaras de pressão descritas em Klute (1986). Após o equilíbrio as amostras foram armazenadas em temperaturas de $\pm 5^{\circ} \mathrm{C}$ por aproximadamente um mês, de modo a garantir a distribuição uniforme da umidade do solo no interior dos anéis, para realização das medidas de RP.



Figura 1 - Áreas onde foram realizadas as amostragens, em (a) piquete no sistema de pastejo rotacionado, em (b) detalhe mostrando as posições espaciais touceira $[t]$ e entre touceiras $[e]$, em (c) piquete no sistema de pastejo contínuo e (d) cerrado. 
A determinação da RP foi realizada em cada uma das amostras indeformadas, com três repetições por amostra, totalizando 630 ensaios de RP (210 amostras x 3 repetições). Para tal fim foi utilizado um penetrômetro desenvolvido no Laboratório de Física do Solo da ESALQ/USP. Conforme descrito por Tormena (1998) o penetrômetro é composto por um atuador linear elétrico com motor de passo; um painel para controle da velocidade e direção de deslocamento; uma base metálica para sustentação do conjunto mecânico e da amostra durante o teste; e uma célula de carga com capacidade nominal de $20 \mathrm{~kg}$ acoplada na extremidade do braço mecânico atenuador. Na extremidade do braço mecânico é localizada uma haste, com um cone na extremidade, os quais são inseridos através do solo para determinação da RP. O cone possui semiângulo de penetração de $30^{\circ}$ e área da base de $0,1167 \mathrm{~cm}^{2}$. As leituras são enviadas diretamente para um sistema automático de aquisição de dados, e são gravadas em formato de arquivo de texto. Os valores de RP são coletados pelo sistema a cada 0,6767 segundos.

Foi adotada a velocidade de penetração de 1,0 $\mathrm{cm} \mathrm{min}^{-1}$ Bradford (1980), até a profundidade de 4,0 $\mathrm{cm}$. Foram selecionados os valores de RP correspondentes à profundidade de 1,0 a 3,0 cm. Os valores adquiridos em kgf foram então transformados em MPa, e foi calculada a média aritmética dos valores para cada ensaio. Como foram realizados três ensaios por amostra, a média aritmética dos resultados destes ensaios correspondeu ao valor da RP para cada amostra.

Imediatamente após os ensaios as amostras foram pesadas e colocadas em estufa a $105^{\circ}$ por um período de 24 horas para determinação da umidade gravimétrica $\left(\theta_{\mathrm{G}}\right)$ (Gardner, 1986) e $D s$ (Blake \& Hartge, 1986), a $\theta_{\mathrm{V}}$ é obtida multiplicando-se a umidade gravimétrica pela densidade relativa do solo (densidade do solo/densidade da água), em $\mathrm{g} \mathrm{cm}^{-3}$ (Libardi, 2000).

Com o gradiente de tensão ao qual as amostras são submetidas obtém-se um gradiente de $\theta_{\mathrm{V}}$ e consequentemente um gradiente de RP, sendo este o princípio das curvas de retenção de água e de resistência à penetração do solo.

Para o ajuste dos modelos foram selecionados 50 valores de densidade do solo dos 210 inicialmente obtidos. Para isto foi determinada a amplitude de variação dos 
valores de $D s$ considerando-se todos os tratamentos. Esta amplitude total foi dividida em cinco faixas, e em cada faixa foram escolhidos aleatoriamente 10 valores de $D s$, cada um correspondente a uma das 10 tensões aplicadas para realização da curva de retenção de água no solo. Para cada valor de $D s$ corresponderam um valor de RP e um de $\theta_{\mathrm{V}}$. Este procedimento foi realizado para garantir uma distribuição uniforme dos valores de $D s$ a serem utilizados nos ajustes, uma vez que tende a haver uma concentração de valores mais elevados de $D s$ em tratamentos que recebem uso e manejo.

A curva de retenção de água no solo foi ajustada utilizando a função empregada por Silva et al. (1994):

$$
\theta_{\mathrm{V}}=a|\psi|^{b}
$$

Na qual:

$\theta_{\mathrm{V}}=$ Conteúdo volumétrico de água no solo $\left(\mathrm{cm}^{3} \mathrm{~cm}^{-3}\right)$;

$|\psi|=$ Tensão de água no solo $(\mathrm{hPa})$;

$a$ e $b=$ Parâmetros do ajuste do modelo.

A Ds foi incorporada no modelo através do parâmetro $a$ o qual foi definido como: $a=a_{0} D s^{a l}$; sendo $a_{0}$ e $a_{l}$ parâmetros provenientes do ajuste não linear do modelo.

A curva de resistência do solo à penetração foi ajustada utilizando a função proposta por Busscher (1990) e empregada por Silva et al. (1994):

$$
\mathrm{RP}=c \theta_{\mathrm{V}}^{d} D s^{e}
$$

ou, a transformação logarítmica:

$$
\ln R \mathrm{P}=\ln c+d \ln \theta_{\mathrm{V}}+e \ln D s
$$

Na qual:

$\mathrm{RP}=$ Resistência do solo à penetração $(\mathrm{MPa})$;

Ds = Densidade do solo $\left(\mathrm{g} \mathrm{cm}^{-3}\right)$;

$c, d$, e $e=$ Parâmetros do ajuste do modelo.

Foram realizadas análises de regressão linear múltipla (Neter et al., 1989) e regressão não linear múltipla (Ratkowsky, 1990) aplicando o método dos resíduos "studentizados" para detecção de outliers na regressão (SAS Institute, 1991). Os procedimentos foram realizados através das rotinas "REG" e "NLIN" do sistema 
SAS/STAT $^{\circledR}$ (SAS Institute, 1999) e os gráficos através do sistema SAS/GRAPH ${ }^{\circledR}$ (SAS Institute, 2000).

Através da regressão dos mínimos quadrados são estimados valores para os parâmetros em cada um dos modelos. A curva de retenção de água no solo foi caracterizada através da eq. (1), sendo o ajuste realizado por regressão não linear, empregando o algoritmo de Leverberg-Marquardt. A curva de resistência à penetração foi caracterizada empregando-se o modelo linearizado apresentado na eq. (3) sendo o ajuste realizado através de regressão linear. Uma vez determinados os valores estimados para os parâmetros $a_{0}, a_{l}, b, c, d$, e $e$ eles são substituídos nas eq. (1 e 3), sendo que a eq. (3) deve ser convertida na eq. (2), aplicando-se o antilogaritmo. Assumindo-se a capacidade de campo como o valor de tensão de água de $100 \mathrm{hPa}$ e o ponto de murcha permanente em $15000 \mathrm{hPa}$, a variação da umidade na capacidade de campo $\left(\theta_{\mathrm{CC}}\right)$ e no ponto de murcha permanente $\left(\theta_{\mathrm{PMP}}\right)$ com a $D s$ (eq. 4 e 5) pode ser estimada para determinação do IHO.

$$
\begin{aligned}
& \theta_{\mathrm{CC}}=a_{0} D s^{a l} 100^{b} \\
& \theta_{\mathrm{PMP}}=a_{0} D s^{a l} 15000^{\mathrm{b}}
\end{aligned}
$$

Rearranjando-se a eq. (2), e assumindo-se o valor de RP de 2,5 MPa como limitante ao crescimento de plantas, pode-se avaliar como a umidade em que a RP atinge os 2,5 $\mathrm{MPa}\left(\theta_{\mathrm{RP}}\right)$ varia em função da $D s$.

$$
\theta_{\mathrm{RP}}=\left(2,5 /\left(c D s^{e}\right)\right)^{1 / d}
$$

A porosidade de aeração é calculada para cada amostra como a diferença entre o conteúdo de água com o solo saturado $\left(\theta_{\mathrm{SAT}}\right)$, calculado à partir da $D s$, empregando a eq. (7), e o conteúdo observado de água.

$$
\theta_{\mathrm{SAT}}=(1-D s / D p)
$$

Na qual:

$D p=$ Densidade de partículas, assumida como $2,65 \mathrm{~g} \mathrm{~cm}^{-3}$.

A umidade em que a porosidade de aeração é igual a $10 \%\left(\theta_{\mathrm{PA}}\right)$ é calculada através da eq. (8).

$$
\theta_{\mathrm{PA}}=\theta_{\mathrm{SAT}}-0,1
$$


O IHO é determinado através das eq. (4, 5, 6 e 8) (Figura 2). Como a única variável independente é a $D s$ em todos os modelos, o IHO é definido como a diferença entre o limite superior, que pode ser associado à umidade do solo na capacidade de campo [Figura 2(a)] ou a umidade em que porosidade de aeração é menor que $10 \%$ [Figura 2(b)]; e o limite inferior, determinado pela umidade em que a RP atinge os 2,5 $\mathrm{MPa}$ [Figura 2(c)] ou pela umidade do solo no ponto de murcha permanente [Figura 2(d)]. Para o limite superior considera-se sempre o menor valor de umidade e para o limite superior sempre o maior valor de umidade.

Os valores críticos para o crescimento de pastagens associados a RP, $|\psi|$ e PA apresentados anteriormente foram definidos de acordo com a literatura. A capacidade de campo foi assumida como a umidade do solo na tensão de $100 \mathrm{hPa}$ (Haise et al., 1955), e o ponto de murcha permanente na tensão de $15000 \mathrm{hPa}$ (Richards \& Weaver, 1944). O valor de RP assumido como limitante para o crescimento de plantas foi o de 2,5 $\mathrm{MPa}$ (Imhoff et al., 2000a) e a porosidade de aeração limitante foi de 10\% (Grable \& Siemer, 1968). 



Figura 2 - Representação do IHO considerando o limite superior, definido pela umidade do solo na capacidade de campo (a), ou umidade em que a porosidade de aeração é menor que $10 \%$ (b); e o limite inferior, definido pela umidade em que a RP é igual a 2,5 MPa (c) ou pela umidade do solo no ponto de murcha permanente (d); em (e) observa-se o IHO como a conjunção dos limites. 


\section{RESULTADOS E DISCUSSÃO}

\subsection{Intervalo Hídrico Ótimo}

A distribuição estatística das variáveis físicas do solo empregadas no ajuste dos modelos de retenção de água e resistência do solo à penetração é apresentada na Tabela 1. Os valores médios das variáveis estão de acordo com aqueles encontrados por Tormena et al. (1998) em um Latossolo muito argiloso. Os valores mais elevados para o desvio padrão podem ser atribuídos à maior amplitude de variação da $D s$ encontrada neste estudo.

Tabela 1. Distribuição estatística das variáveis físicas do solo utilizadas nos ajustes dos modelos.

\begin{tabular}{cccccc}
\hline Variável & $\mathrm{N}$ & Média & Desvio Padrão & Mínimo & Máximo \\
\hline $\mathrm{RP}^{\S}$ & 50 & 1,892 & 1,374 & 0,262 & 6,531 \\
Ds$^{*}$ & 50 & 1,17 & 0,20 & 0,81 & 1,52 \\
$\theta_{\mathrm{V}}{ }^{\mathbb{I l}}$ & 50 & 0,300 & 0,071 & 0,185 & 0,460 \\
\hline${ }^{8}$ & & & & &
\end{tabular}

${ }^{8}$ Resistência do solo à penetração, MPa ; * Densidade do solo, $\mathrm{g} \mathrm{cm}^{-3}$; ${ }^{\mathrm{I}}$ Umidade volumétrica, $\mathrm{cm}^{3} \mathrm{~cm}^{-3}$.

Na Tabela 2 são apresentados os coeficientes resultantes do ajuste não linear da curva de retenção de água no solo, empregando-se a eq. (1). Os coeficientes mostram que a umidade do solo variou positivamente com a densidade do solo e negativamente com a tensão de água no solo. O intervalo de confiança não incluiu o valor zero, indicando que todos os coeficientes são estatisticamente significativos (Glantz \& Slinker, 1990). 
Tabela 2. Coeficientes resultantes do ajuste não linear da curva de retenção de água no solo: $\theta_{\mathrm{V}}=a_{0} D s^{a 1}|\psi|^{b}$

\begin{tabular}{ccccc}
\hline Coeficiente & Valor & Erro Padrão & \multicolumn{2}{c}{ Intervalo de confiança } \\
\cline { 4 - 5 } & & & Inferior & Superior \\
\hline$a_{0}$ & 0,5219 & 0,0207 & 0,4804 & 0,5635 \\
$a_{1}$ & 0,5172 & 0,0689 & 0,3787 & 0,6558 \\
$b$ & $-0,1179$ & 0,00752 & $-0,1331$ & $-0,1028$ \\
\hline
\end{tabular}

$\theta_{\mathrm{V}}=$ Umidade volumétrica, $\mathrm{cm}^{3} \mathrm{~cm}^{-3} ; D s=$ Densidade do solo, $\mathrm{g} \mathrm{cm}^{-3} ;|\psi|=$ Tensão de água no solo, $\mathrm{hPa} ;$ $\mathrm{R}^{2}=0,87 ; \mathrm{N}=50$.

Substituindo-se os coeficientes apresentados na Tabela 2 nas equações 4 e 5 foi possível calcular a variação da umidade do solo na capacidade de campo e no ponto de murcha permanente, tendo como variável independente a $D s$.

$$
\begin{aligned}
& \theta_{\mathrm{CC}}=0,5219 D s^{0,5172} 100^{-0,1179} \\
& \theta_{\mathrm{PMP}}=0,5219 D s^{0,5172} 15000^{-0,1179}
\end{aligned}
$$

Os coeficientes resultantes do ajuste linear do modelo de resistência do solo à penetração descrito pela eq. (3) são apresentados na Tabela 3. Os sinais apresentados pelos coeficientes indicaram que a resistência do solo à penetração variou positivamente com a $D s$ e negativamente com a $\theta_{\mathrm{V}}$, concordando com diversos outros estudos (Betz et al. 1998; Imhoff et al., 2000b; Silva et al., 1994; Tormena et al. 1999). A diminuição da RP com o aumento da $\theta_{\mathrm{V}}$ pode ser atribuída à redução da coesão e do ângulo de fricção interna, causados pela elevação do conteúdo de água (Camp \& Gill, 1969). O aumento da RP com o aumento da Ds está relacionado ao efeito na matriz do solo ocasionado pela compactação, aliado ao aumento da coesão causado pela ação da umidade do solo entre as partículas que ficam mais próximas à medida que o solo é compactado (Sojka et al., 2001).

Os coeficientes apresentados na Tabela 3 foram determinados através do ajuste linear da eq. (3) e, deste modo, para que pudessem ser substituídos na eq. (6) foi necessário aplicar o antilogaritmo ao coeficiente $c$. Uma vez realizado este procedimento 
a eq. (6) pôde ser utilizada para estimar a variação da umidade em que a RP do solo atinge 2,5 MPa tendo como variável independente a $D s$ (eq. 11).

Tabela 3. Coeficientes resultantes do ajuste linear da curva de resistência do solo à penetração: $\ln R P=\ln c+d \ln \theta_{\mathrm{V}}+e \ln D s$

\begin{tabular}{ccccc}
\hline Coeficiente & Valor & Erro Padrão & $\mathrm{t}$ & Prob. $>|\mathrm{t}|$ \\
\hline$c$ & $-1,9281$ & 0,2113 & $-9,13$ & $<0,0001$ \\
$d$ & $-1,3670$ & 0,1573 & $-8,69$ & $<0,0001$ \\
$e$ & 4,5036 & 0,2140 & 21,05 & $<0,0001$ \\
\hline
\end{tabular}

$\mathrm{RP}=$ Resistência do solo à penetração, $\mathrm{MPa} ; \theta_{\mathrm{V}}=$ Umidade volumétrica, $\mathrm{cm}^{3} \mathrm{~cm}^{-3} ; D s=$ Densidade do solo, $\mathrm{g} \mathrm{cm}^{-3}, \mathrm{r}^{2}=0,90 ; \mathrm{N}=50$.

$$
\theta_{\mathrm{RP}}=\left(2,5 /\left(0,1454 D s^{4,5036}\right)\right)^{1 /-1,3670}
$$

A Figura 3 foi obtida plotando-se as equações 8, 9, 10 e 11 em um mesmo sistema de coordenadas $x$ e $y$, o eixo $x$ representando a $D s$, em $\mathrm{g} \mathrm{cm}^{-3}$, e o eixo $y$ a umidade do solo, em $\mathrm{cm}^{3} \mathrm{~cm}^{-3}$. Ela representa portanto a variação da umidade do solo nos limites críticos definidos por $\theta_{\mathrm{CC}}, \theta_{\mathrm{RP}}, \theta_{\mathrm{PA}}$ e $\theta_{\mathrm{PMP}}$ em função da $D s$. O IHO corresponde a área hachurada no gráfico tendo sido definido em seu limite superior pela $\theta_{\mathrm{CC}}$, e em seu limite inferior pela $\theta_{\mathrm{PMP}}$ ou $\theta_{\mathrm{RP}}$. A amplitude total de variação do IHO foi de 0,01386 até $0,1423 \mathrm{~cm}^{3} \mathrm{~cm}^{-3}$. A umidade retida na capacidade de campo aumentou com a densidade do solo, comportamento também observado por Silva et al. (1994) em um solo arenoso, Betz et al. (1998) em um solo franco, e por Tormena et al. (1999) em um solo muito argiloso.

Nos Latossolos, o processo de compactação geralmente não afeta a porosidade presente no interior dos microagregados, porém os macroporos localizados entre os agregados têm seu diâmetro reduzido, passando a atuar na retenção de água, e deste modo contribuindo para o aumento da quantidade de água retida nas baixas tensões (Kertzman, 1996). Este comportamento é inverso ao observado em outros tipos de solos (van den Berg et al., 1997), o que pode ser atribuído ao tipo de estrutura dos Latossolos, na qual as partículas primárias estão unidas em microagregados muito estáveis com 
tamanho correspondente à fração areia, estabilidade esta associada ao efeito cimentante de óxidos de ferro e alumínio, e da matéria orgânica (Sanchez, 1976). A presença de microagregados estáveis em solos não perturbados por práticas de manejo proporciona uma elevada porosidade total, formada em grande parte por macroporos, os quais não atuam diretamente no processo de retenção de água, agindo principalmente na drenagem e aeração do solo (Brady \& Weil, 1999).

A retenção de água em baixas tensões é função da estrutura do solo, uma vez que varia com o tipo e o diâmetro da porosidade presente. Por outro lado, a retenção de água em tensões elevadas é função da textura do solo, correspondendo à água retida em poros de dimensões microscópicas e em películas muito finas ao redor das partículas individuais de solo (Brady \&Weil, 1999). Deste modo, o aumento do conteúdo de água retido no ponto de murcha permanente com o incremento da densidade do solo pode ser atribuído ao aumento do número de partículas disponíveis para a retenção de água por unidade de volume de solo, decorrente da compactação (van den Berg, 1997).

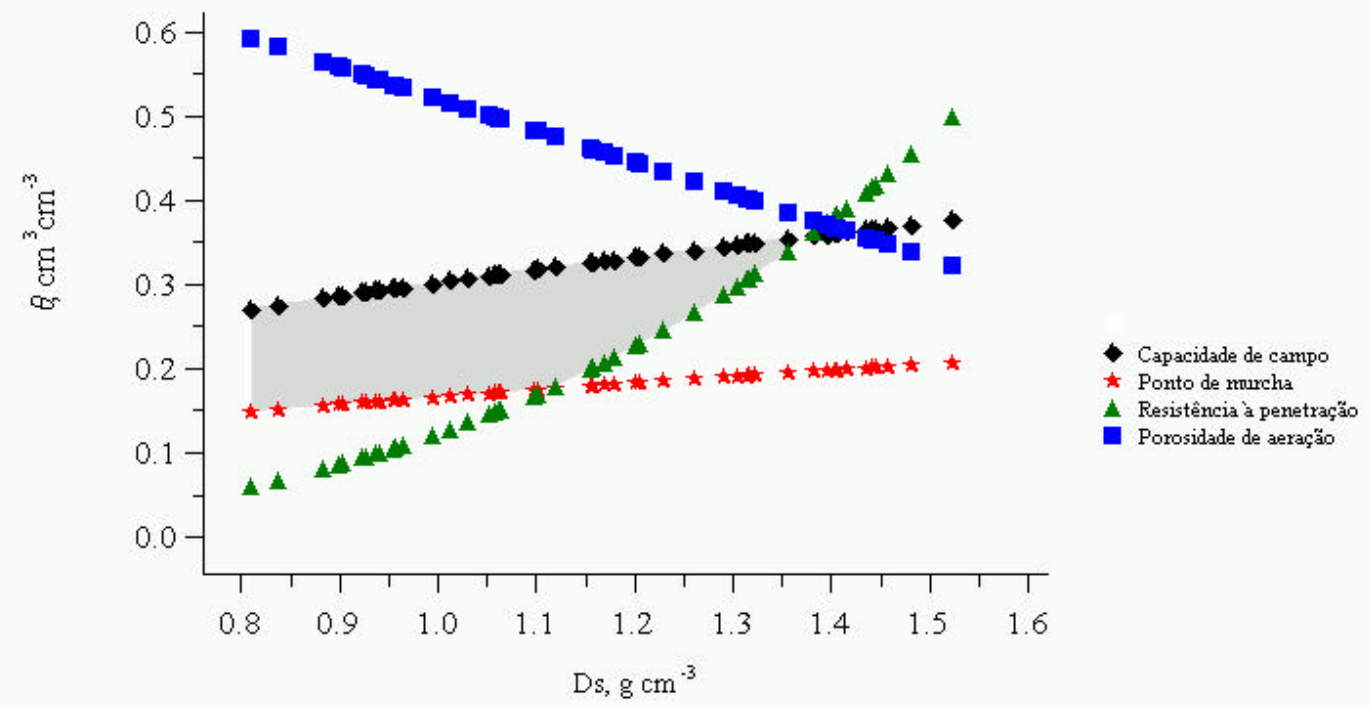

Figura 3 - Variação do conteúdo de água com a densidade nos níveis críticos da capacidade de campo $(|\psi|=100 \mathrm{hPa})$, ponto de murcha permanente $(|\psi|=$ $15000 \mathrm{hPa}$ ), porosidade de aeração de $10 \%$ e resistência à penetração de 2,5 MPa; no Latossolo Vermelho Distrófico argiloso estudado. A área hachurada representa o Intervalo Hídrico Ótimo (IHO). 
Como pode ser verificado pela Figura 4 o IHO aumentou até a $D s$ de $1,11 \mathrm{~g} \mathrm{~cm}^{-3}$, quando a $\theta_{\mathrm{RP}}$ substituiu a $\theta_{\mathrm{PMP}}$ como limite inferior, sendo este valor similar ao encontrado por Tormena et al. (1999) em um Latossolo muito argiloso sob sistema de cultivo convencional de milho. A $\theta_{\mathrm{PA}}$ não representou limitação ao crescimento de plantas no solo estudado até a $D s$ de $1,42 \mathrm{~g} \mathrm{~cm}^{-3}$, o que pode ser atribuído à elevada porosidade total presente nos Latossolos, onde problemas de aeração são verificados apenas em casos de compactação severa, excesso de umidade e elevado conteúdo de argila.

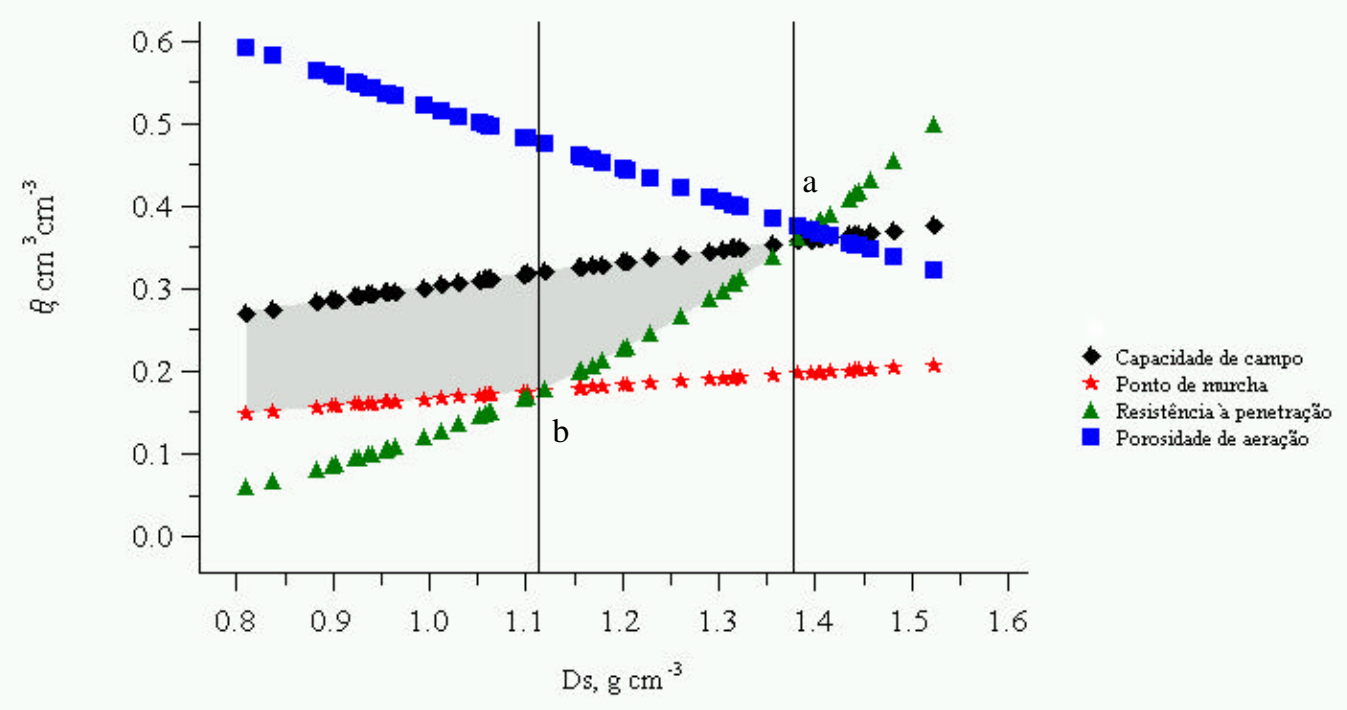

Figura 4 - Variação do conteúdo de água com a densidade nos níveis críticos da capacidade de campo $(|\psi|=100 \mathrm{hPa})$, ponto de murcha permanente $(|\psi|=$ $15000 \mathrm{hPa}$ ), porosidade de aeração de $10 \%$ e resistência à penetração de 2,5 MPa; no Latossolo Vermelho Distrófico argiloso estudado. A área hachurada representa o Intervalo Hídrico Ótimo (IHO). A densidade crítica $(D s c)$, onde o IHO = 0, é demonstrada em (a), e a densidade em que a resistência à penetração substitui o ponto de murcha permanente como limite inferior do IHO em (b). 
A densidade crítica $(D s c)$ corresponde ao valor de $D s$ no qual o IHO é igual a zero, sendo definida pela interseção das equações que determinam os limites superior e inferior do IHO. Neste estudo a densidade em que a $\theta_{\mathrm{PA}}$ substituiu a $\theta_{\mathrm{CC}}$ como limite superior do IHO foi superior à $D s c$, o que também foi verificado por Silva et al. (1994) e Tormena et al. (1999).

A Dsc correspondeu à interseção da $\theta_{\mathrm{CC}} \mathrm{com}$ a $\theta_{\mathrm{RP}}$, sendo igual a $1,38 \mathrm{~g} \mathrm{~cm}^{-3}$ (Figura 4). Este valor é superior ao encontrado por Tormena et al. (1999), o que pode ser atribuído ao modelo utilizado por aqueles autores para a retenção de água e ao valor de RP limitante adotado, que foi de 2,0 MPa. Tormena et al. (1998) utilizaram um modelo de retenção de água matematicamente similar ao adotado neste trabalho encontrando um valor de Dsc semelhante para o valor crítico de RP de 2,5 MPa. Betz et al. (1998), Imhoff et al. (2001) e Silva et al. (1994) encontraram valores mais elevados para a Dsc o que pode ser atribuído aos diferentes tipos de solos utilizados nos experimentos.

O IHO é um índice que integra os efeitos do status de aeração, da disponibilidade de água, e da resistência mecânica à penetração de raízes, proporcionados pelo solo ao crescimento de plantas em função de uma única variável; a Ds. Aeração, disponibilidade de água e resistência à penetração são afetados por propriedades intrínsecas do solo, como textura, mineralogia, características do perfil, etc., e por propriedades passíveis de serem alteradas pelo manejo, como densidade do solo e matéria orgânica. Todos os tratamentos analisados neste experimento situaram-se em um mesmo tipo de solo, sem variações consideráveis nos conteúdos de argila e matéria orgânica, razão pela qual foi possível caracterizar um único IHO, considerando amostras provenientes de todo o experimento, e em seguida situar cada um dos tratamentos dentro da amplitude de variação do IHO, de acordo com os valores de $D s$ observados.

Em experimentos com variações consideráveis das propriedades físicas, físicoquímicas e/ou morfológicas do solo entre tratamentos é conveniente que o ajuste dos modelos de retenção de água e resistência do solo à penetração deva ser realizado empregando-se métodos estatísticos adequados para avaliação do grau de influência de tais propriedades sobre o comportamento do IHO, conforme demonstrado por Silva et al. (1994). 


\subsection{Intervalo Hídrico Ótimo entre tratamentos}

A condição física do solo para o crescimento de plantas em cada um dos tratamentos é analisada em função da distribuição dos valores de $D s$ dentro da amplitude de variação do IHO conforme pode ser observado nas Figuras 5 a 10. As colunas verticais representam a média dos valores de $D s \pm$ um desvio padrão.

$\mathrm{O}$ cerrado $(\mathrm{CN})$ apresentou a melhor condição física do solo para o crescimento de plantas, não sendo observadas limitações quanto à resistência do solo à penetração. No $\mathrm{CN}$ o IHO correspondeu à água disponível, o que significa que o limite superior foi definido pela $\theta_{\mathrm{CC}}$ e o limite inferior pela $\theta_{\mathrm{PMP}}$ (Figuras 5 a 10). A melhor qualidade física de solos sob vegetação nativa em relação a solos cultivados com pastagens também foi observada por Correa \& Reichardt (1995) e Muller et al. (2001). Além do efeito direto do pisoteio dos animais sobre as propriedades físicas do solo, a implantação de sistemas de pastejo também provoca efeitos indiretos, uma vez que reduz a população de organismos do solo responsáveis pela melhoria destas propriedades (Alegre \& Cassel, 1996).

Os piquetes no sistema de pastejo contínuo, com adubação de manutenção $(\mathrm{Cc})$ e sem adubação de manutenção (Cs), apresentaram condições semelhantes, no que diz respeito aos valores de $D s$ e ao IHO. A presença ou não de adubação de manutenção não exerceu efeito significativo sobre as propriedades físicas do solo no sistema de pastejo contínuo estudado. Isto pode ser atribuído aos valores similares das taxas de lotação animal empregadas, cujas médias de seis anos foram de 1,53 $\mathrm{UA} \mathrm{ha}^{-1}$ e 1,68 UA ha ${ }^{-1}$ para Cs e Cc, respectivamente. As doses de adubação empregadas no Cc não foram suficientes para provocar um crescimento mais intenso da parte aérea das plantas, pois o

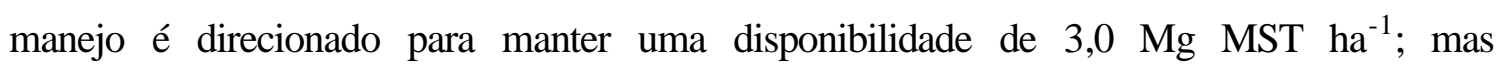
estariam estimulando o crescimento radicular, melhorando as propriedades físicas do solo à longo prazo. Para que houvessem diferenças significativas nas propriedades físicas entre Cc e Cs haveria necessidade de um incremento ainda maior na taxa de lotação animal, havendo necessidade de mais estudos sobre a interação entre dose de adubação e taxa de lotação animal sobre as propriedades físicas do solo. 
Uma vez que não foram detectadas diferenças significativas entre os tratamentos $\mathrm{Cc}$ e Cs, e por haver um consenso de que a maioria dos produtores que trabalha com pastejo contínuo em Brachiaria decumbens não realiza investimentos consideráveis no sistema, o que inclui a realização adubações de manutenção (Macedo, 2001), as comparações entre os sistemas de pastejo contínuo e rotacionado foram realizadas utilizando-se o tratamento Cs como referência.

$\mathrm{Na}$ Figura 5 pode-se observar a comparação entre Cs e o sistema de pastejo rotacionado, resíduo de 2,0-2,5 $\mathrm{Mg} \mathrm{MST} \mathrm{ha}^{-1}$, considerando amostras retiradas na posição espacial entre touceiras (R1e), tendo como referência o $\mathrm{CN}$. O R1e apresentou condições físicas do solo para o crescimento de plantas muito inferiores ao Cs, sendo que a maior parte da faixa de valores de $D s$ localizou-se acima da Dsc. Este resultado discorda daquele encontrado por Proffitt et al. (1995b) em experimento comparando os sistemas de pastejo contínuo e controlado, implantados em um solo de textura média, e pastejados por ovelhas. Ao fim do período experimental, os autores observaram que todos os atributos estruturais medidos ( $D s$, taxas de infiltração, resistência tênsil, e aqueles obtidos por análise de imagens) indicaram que a qualidade física da camada superficial do solo sob sistema de pastejo controlado era superior a do sistema de pastejo contínuo, sendo similar ao tratamento não pastejado.

No sistema de pastejo controlado avaliado por Proffitt et al. (1995b) os animais eram retirados da área quando o solo se aproximava do limite de plasticidade, sendo esta a possível razão pela qual esse sistema obteve um melhor resultado quando comparado com o sistema de pastejo contínuo.

O entendimento do conceito do limite de plasticidade é de fundamental importância para o manejo físico de sistemas de pastejo rotacionado, onde as taxas de lotação animal são normalmente elevadas (Tanner \& Mamaril, 1959). O limite de plasticidade corresponde ao limite inferior da faixa de umidade do solo na qual ele possui consistência plástica. A plasticidade é uma característica das argilas que, ao serem umedecidas, formam uma massa que pode ser deformada com a aplicação de uma determinada força e que mantêm a deformação imposta mesmo após a remoção da água (Baver et al., 1972). Deste modo, o tráfego ou pisoteio em condições de plasticidade 
provoca danos estruturais ao solo (Dexter \& Bird, 2001), incluindo redução da porosidade total, destruição dos agregados, e consequentemente, compactação. Em solos destinados à agricultura, a relação entre umidade do solo e susceptibilidade à compactação pelo tráfego têm sido avaliada em termos de trabalhabilidade e trafegabilidade do solo (Earl, 1997; Imhoff, 2002; Müller et al., 1990), podendo-se fazer um paralelo entre a trafegabilidade do solo às máquinas agrícolas e aos animais, onde as necessidades de restrição ao tráfego em condições de umidade elevada são aplicáveis.

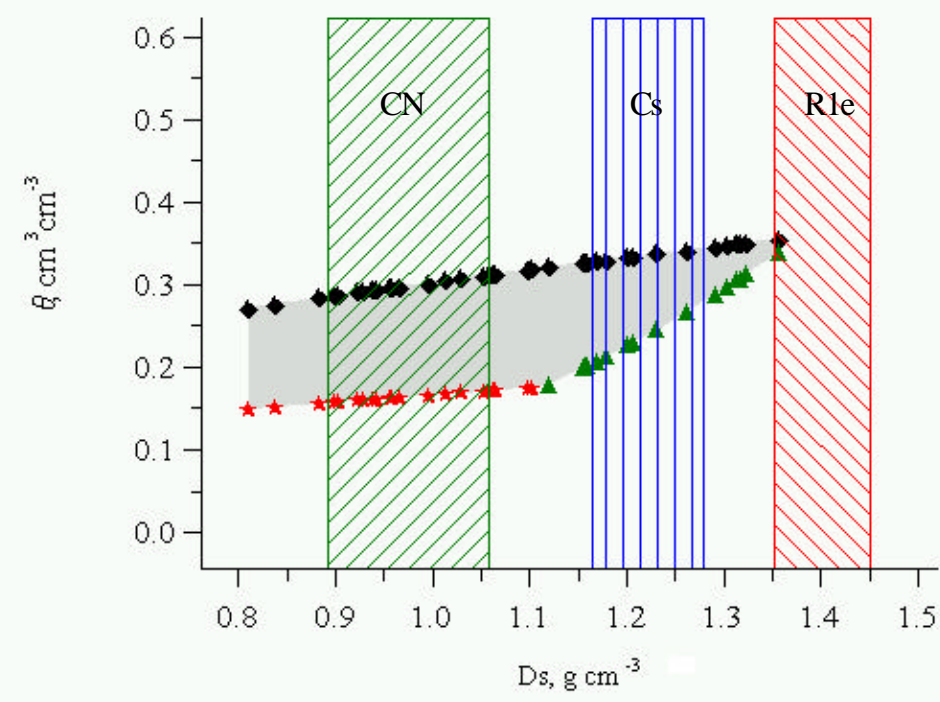

- Capacidade de campo

* Ponto de rourcha

- Resistência à penetração

Figura 5 - Comparação entre o sistema de pastejo contínuo, sem adubação de manutenção (Cs) e o sistema de pastejo rotacionado, resíduo pós pastejo de 2,0-2,5 Mg MST ha ${ }^{-1}$, considerando amostras retiradas na posição espacial entre touceiras (R1e). A área hachurada corresponde ao Intervalo Hídrico Ótimo $(\mathrm{IHO})$ e as colunas verticais correspondem à média dos valores de $D s \pm$ um desvio padrão. ( $\mathrm{CN}=$ cerrado).

O hábito de crescimento cespitoso da espécie Panicum maximum cv. Tanzânia presente no R1e também pode ter contribuído para o aumento da $D s$, uma vez que o solo entre as touceiras se encontrava completamente descoberto, estando sujeito ao impacto direto das patas dos animais. Por sua vez, o hábito de crescimento decumbente da 
espécie Brachiaria decumbens cv. Basilisk implantada no Cs, proporciona uma tendência de cobertura total da superfície do solo, minimizando o impacto do pisoteio dos animais. Segundo Trimble \& Mendel (1995) a força aplicada pelos cascos dos animais é normalmente subestimada por ser concebida como estática, no entanto, ao se movimentar o animal transfere a massa do corpo para uma ou duas de suas patas, além do efeito agravante da aceleração desenvolvida no movimento. Deste modo, a cobertura do solo com material vegetal deve exercer um efeito de amortecimento, minimizando a ação direta dos impactos dos cascos dos animais sobre o solo.

Chanasyk \& Naeth (1995) comparando sistemas de pastejo contínuo e rotacionado implantados em um solo franco-argiloso observaram que o sistema de pastejo contínuo causou maior degradação das propriedades físicas do solo em relação ao sistema de pastejo rotacionado, apresentando maiores valores de Ds e RP. No entanto estes resultados podem ser atribuídos à equivalência entre as taxas de lotação nos dois sistemas, o que não ocorreu neste estudo, onde a lotação média para o sistema de pastejo contínuo foi muito inferior à do sistema de pastejo rotacionado.

O sistema de pastejo rotacionado, resíduo de 3,0-3,5 $\mathrm{Mg} \mathrm{MST} \mathrm{ha}^{-1}$, considerando amostras retiradas na posição espacial entre touceiras (R2e), também apresentou uma condição física do solo inferior à do tratamento Cs para o crescimento de plantas, o que pode ser atribuído aos mesmos fatores discutidos anteriormente (Figura 6). No entanto, como pode ser verificado pela Figura 7 as menores taxas de lotação animal empregadas no R2e provocaram danos menos severos ao solo que no R1e. A amplitude de variação da $D s$ correspondente ao R2e situou-se abaixo da $D s c$, no entanto as restrições causadas pela RP são evidenciadas, uma vez que o limite inferior do IHO para este tratamento é representado pela $\theta_{\mathrm{RP}}$. Estes resultados estão em concordância com os dados apresentados por Silva et al. (2002b) onde o aumento na taxa de lotação acima de 4,42 UA ha ${ }^{-1}$ implicou num aumento de $88 \%$ na taxa de variação da RP, ou seja, o aumento na RP com a lotação é muito mais severo em lotações acima de 4,42 UA ha ${ }^{-1}$.

A menor lotação animal, e consequentemente o menor pisoteio e a maior quantidade de resíduos vegetais deixados no tratamento $\mathrm{R} 2$, em torno de 3,0 a $3,5 \mathrm{Mg}$ MST ha- em comparação com os 2,0 a 2,5 $\mathrm{Mg} \mathrm{MST} \mathrm{ha}^{-1}$ deixados no R1 podem ter 
favorecido as propriedades físicas do solo. van Haveren (1983), Warren et al. (1986) e Chanasyk \& Naeth (1995) também observaram uma deterioração das propriedades físicas do solo com o aumento da taxa de lotação animal, sendo o efeito mais acentuado em solos de textura fina. Warren et al. (1986) observaram que o aumento na $D s$ com o incremento da lotação animal foi atribuído, em grande parte, ao realinhamento dos agregados existentes em um arranjo mais compacto, ao invés da destruição mecânica dos agregados pelo pisoteio. Considerando o tipo de estrutura dos Latossolos, formada por microagregados bastante estáveis, é provável que as elevadas taxas de lotação aplicadas nos tratamentos R1 e R2 estejam provocando um efeito semelhante no solo.

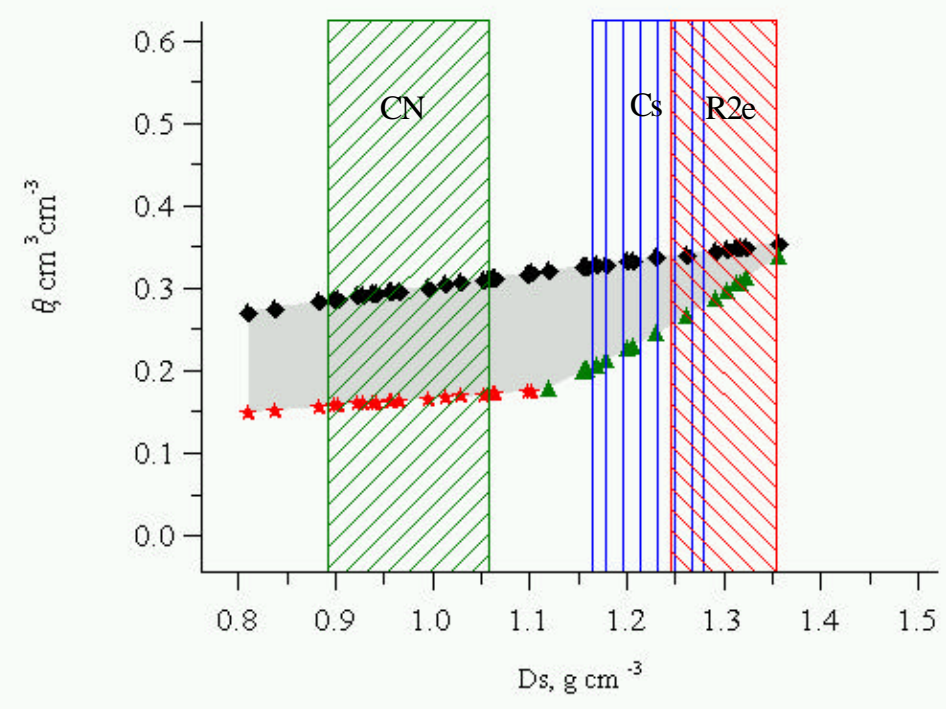

- Capacidade de campo

$\star$ Ponto de rnurcha

- Resistência à penetração

Figura 6 - Comparação entre os sistema de pastejo contínuo, sem adubação de manutenção (Cs) e o sistema de pastejo rotacionado, resíduo pós pastejo de 3,0-3,5 Mg MST ha ${ }^{-1}$, considerando amostras retiradas na posição espacial entre touceiras (R2e). A área hachurada corresponde ao Intervalo Hídrico Ótimo $(\mathrm{IHO})$ e as colunas verticais correspondem à média dos valores de $D s \pm$ um desvio padrão. ( $\mathrm{CN}=$ cerrado).

O efeito da lotação animal sobre o IHO no sistema de pastejo rotacionado se torna menos pronunciado quando são comparadas amostras retiradas na posição espacial 
touceira (Figura 8). Apesar de parte da amplitude de variação da Ds no sistema de pastejo rotacionado, resíduo de 2,0-2,5 $\mathrm{Mg} \mathrm{MST} \mathrm{ha}^{-1}$ (R1t) se encontrar acima da Dsc o efeito é menos drástico do que aquele observado em amostras retiradas na posição espacial entre touceiras (Figura 9). Este resultado também pode ser atribuído ao hábito de crescimento da espécie Panicum maximum cv. Tanzânia formando touceiras sob as quais o solo se encontra protegido do pisoteio, e onde o sistema radicular da planta favorece a melhoria das propriedades físicas do solo, aumentando o conteúdo de matéria orgânica do solo e deslocando as partículas de solo, favorecendo a criação de um microrelevo (Hook et al., 1991), formando as chamadas "ilhas de fertilidade física" (Imhoff et al., 2000a).

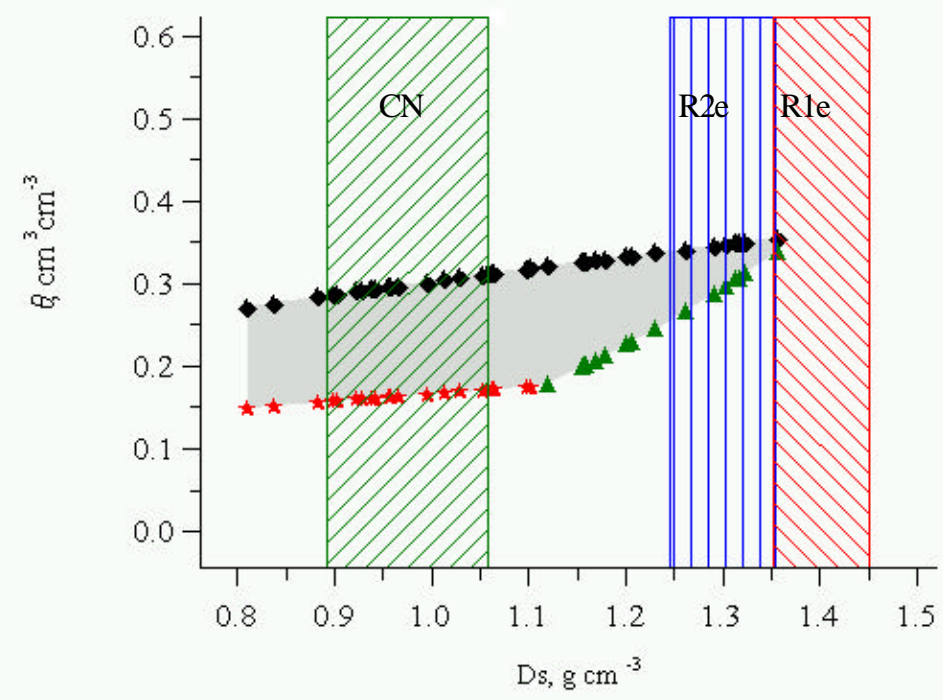

- Capacidade de campo

* Ponto de rumcha

- Resistência à penetração

Figura 7 - Comparação entre piquetes no sistema de pastejo rotacionado: resíduo pós pastejo de 2,0-2,5 $\mathrm{Mg} \mathrm{MST} \mathrm{ha}^{-1}$ (R1e) e resíduo pós pastejo de 3,0-3,5 Mg MST ha ${ }^{-1}$ (R2e), considerando amostras retiradas na posição espacial entre touceiras. A área hachurada corresponde ao Intervalo Hídrico Ótimo (IHO) e as colunas verticais correspondem à média dos valores de $D s \pm$ um desvio padrão. $(\mathrm{CN}=$ cerrado $)$.

O efeito da posição de amostragem (touceira e entre touceiras) sobre o IHO foi 
mais acentuado no R1 (Figura 9) que no R2 (Figura 10). A amplitude de variação da Ds não diferiu significativamente entre as posições touceira e entre touceiras no R2 (média \pm um desvio padrão), localizando-se abaixo da Dsc. O IHO foi definido no limite inferior pela $\theta_{\mathrm{RP}}$ e no limite superior pela $\theta_{\mathrm{CC}}$ em ambas posições espaciais. A diferença de lotação animal durante o período chuvoso de 4,8 UA ha ${ }^{-1}$ no R1 para 4,12 UA ha ${ }^{-1}$ no R2 parece ter sido decisiva na degradação das propriedades físicas do Latossolo estudado, principalmente na posição espacial entre touceiras (Silva et al., 2002b). O aumento da taxa de lotação causou aumento da Ds e redução do IHO, principalmente pelo aumento da umidade do solo em que a RP atinge 2,5 $\mathrm{MPa}$. A deterioração da qualidade física do solo para o crescimento de plantas implica em perdas na produção vegetal, tendo como consequiências a perda da capacidade de suporte da pastagem e a redução da produtividade animal.

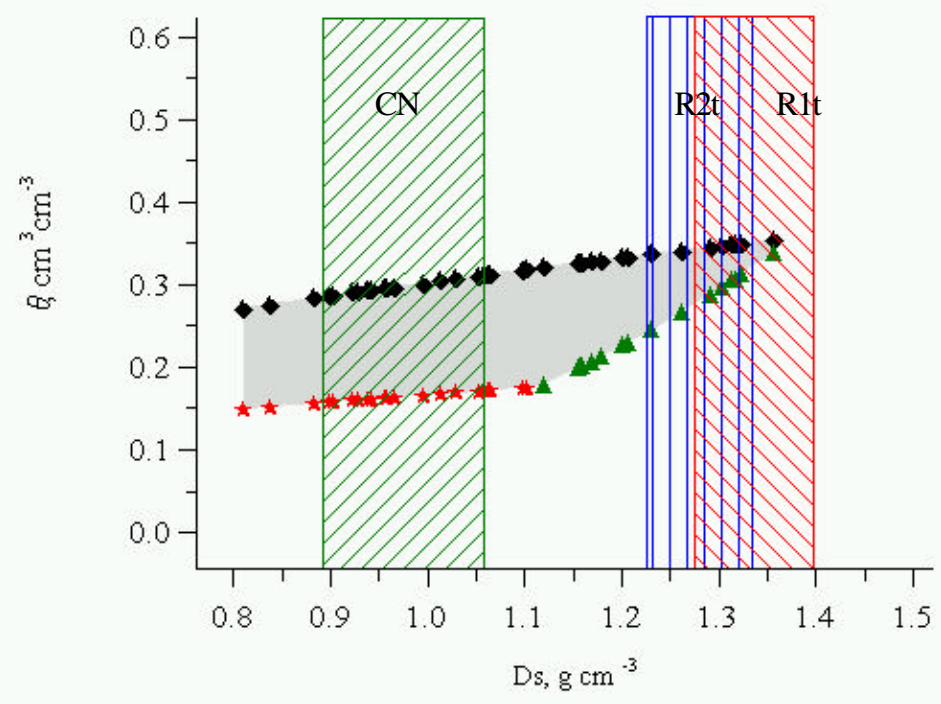

- Capacidade de campo

$\star$ Ponto de ruurcha

A Resistência à penetração

Figura 8 - Comparação entre piquetes no sistema de pastejo rotacionado: resíduo pós pastejo de 2,0-2,5 $\mathrm{Mg} \mathrm{MST} \mathrm{ha}^{-1}$ (R1t) e resíduo pós pastejo de 3,0-3,5 Mg MST ha ${ }^{-1}$ (R2t), considerando amostras retiradas na posição espacial touceira. A área hachurada corresponde ao Intervalo Hídrico Ótimo (IHO) e as colunas verticais correspondem à média dos valores de $D s \pm$ um desvio padrão. $(\mathrm{CN}=$ cerrado $)$. 


\subsection{Distribuição espacial dos valores de densidade do solo}

A distribuição estatística da densidade do solo em cada um dos tratamentos analisados é apresentada na Tabela 4. Os menores valores de Ds são concentrados no $\mathrm{CN}$, sendo que os tratamentos sob sistema de pastejo contínuo apresentaram valores mais baixos de $D s$ que os tratamentos sob sistema de pastejo rotacionado.

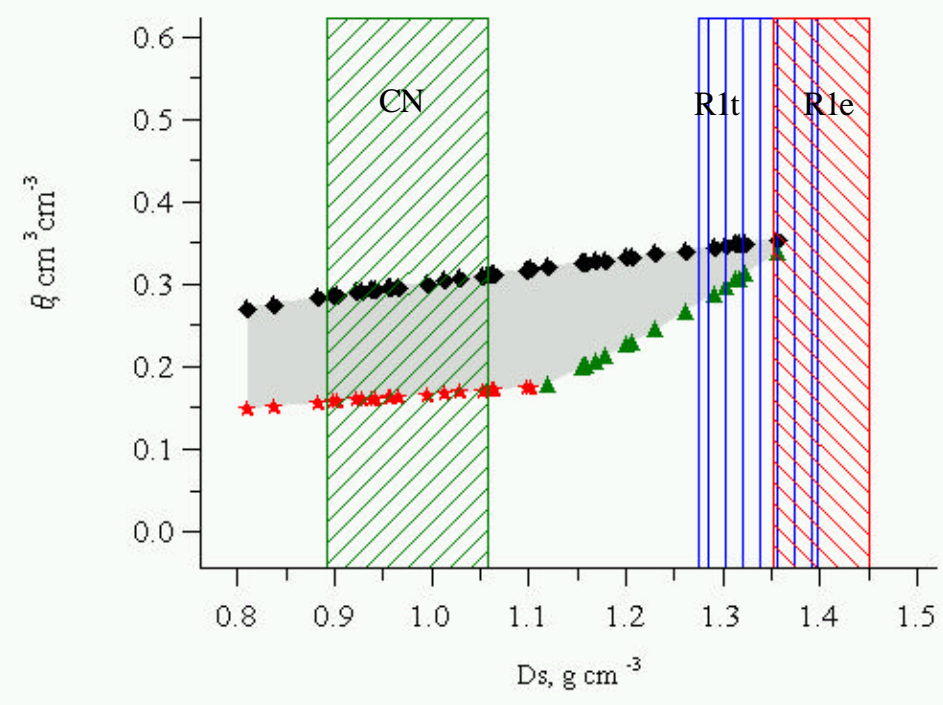

Capacidade de campo

* Ponto de nurcha

- Resistência à penetração

Figura 9 - Comparação entre posições espaciais de amostragem no sistema de pastejo rotacionado, resíduo de 2,0-2,5 $\mathrm{Mg}$ MST ha ${ }^{-1}$ : touceira (R1t) e entre touceiras (R1e). A área hachurada corresponde ao Intervalo Hídrico Ótimo (IHO) e as colunas verticais correspondem à média dos valores de $D s \pm$ um desvio padrão. $(\mathrm{CN}=$ cerrado $)$.

A distribuição espacial dos valores de densidade é representada nas Figuras 11 a 17. Os procedimentos, incluindo as interpolações e a confecção dos gráficos tridimensionais foram realizados através do sistema SAS/GRAPH ${ }^{\circledR}$ (SAS Institute, 2000). A interpolação dos pontos foi realizada através do método "spline" (SAS Institute, 2000). 
Os eixos horizontais das superfícies de $D s$ apresentam as dimensões de 20 x 90 m nos tratamentos CN, Cc e Cs, e 20 x 45 m nos tratamentos R1e, R1t, R2e e R2t, o que se deveu a diferença entre o espaçamento de amostragem, conseqüência da maior área dos piquetes no sistema de pastejo contínuo. Valores de $D s$ superiores à $D s c$ são representados pela coloração vermelha nas superfícies, enquanto que os demais valores são representados pela cor verde. O CN (Figura 11) e os tratamentos sob pastejo contínuo (Figuras 12 e 13) não apresentaram valores de $D s$ superiores à $D s c$.

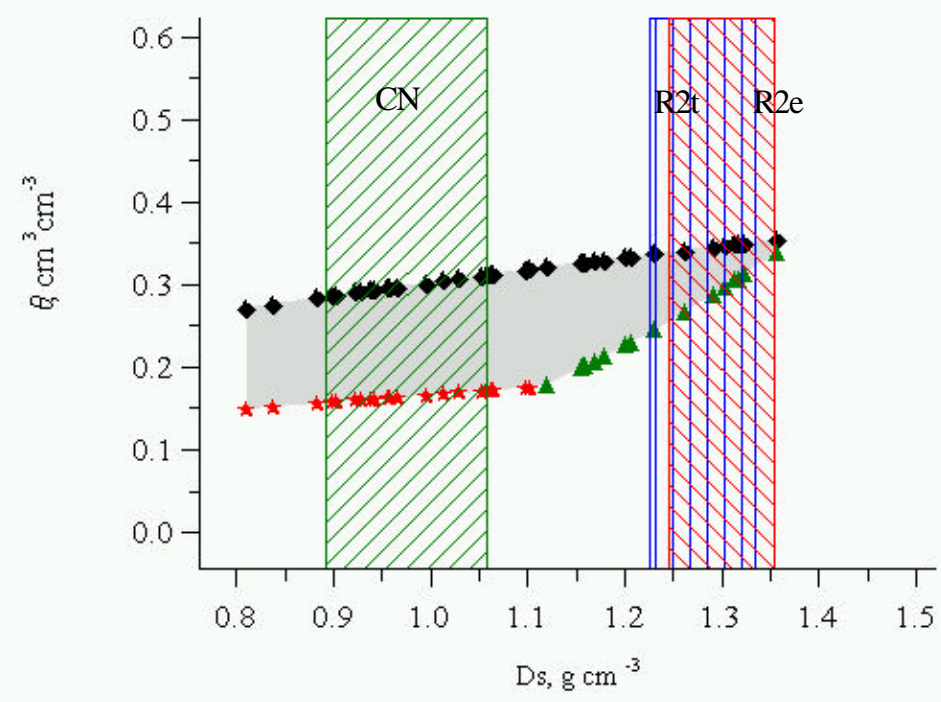

- Capacidade de campo

* Ponto de rourcha

A Resistência à penetração

Figura 10 - Comparação entre posições espaciais de amostragem no sistema de pastejo rotacionado, resíduo de 3,0-3,5 $\mathrm{Mg}$ MST ha ${ }^{-1}$ : touceira (R2t) e entre touceiras (R2e). A área hachurada corresponde ao Intervalo Hídrico Ótimo (IHO) e as colunas verticais correspondem à média dos valores de $D s \pm$ um desvio padrão. $(\mathrm{CN}=$ cerrado $)$.

A $D s c$ foi determinada à partir do $\mathrm{IHO}$, o que significa que as condições físicas do solo são menos limitantes quando a $D s$ é menor que a $D s c$, no que se refere a resistência do solo à penetração, porosidade de aeração, e disponibilidade de água por parte do solo. No entanto, como pode ser visto no item 4.2, o conhecimento somente da Dsc não é suficiente para caracterizar a qualidade física do solo, pois podem ocorrer 
limitações por um IHO muito estreito em valores de $D s$ abaixo da $D s c$. À medida que o IHO se torna mais estreito a probabilidade de que o conteúdo de água do solo atinja valores inadequados para o crescimento de plantas aumenta (Silva \& Kay, 1997b). Assim, para o monitoramento adequado da qualidade física do solo é necessário o conhecimento mais detalhado do comportamento do IHO. Neste trabalho, o valor de $D s$ de $1,11 \mathrm{~g} \mathrm{~cm}^{-3}$ no qual a $\theta_{\mathrm{RP}}$ substitui a $\theta_{\mathrm{PMP}}$ como limite inferior do IHO, e em que o IHO começa a decrescer, representa um valor de advertência à partir do qual devem ser tomadas maiores precauções no que se refere ao manejo do solo para evitar o agravamento do problema de compactação. Conforme demonstraram Silva \& Kay (1997b) o valor de $D s$ em que a $\theta_{\mathrm{PA}}$ substitui a $\theta_{\mathrm{CC}}$ como limite superior também deve ser levado em consideração m análise do IHO, o que não ocorreu neste estudo onde o limite superior é representado pela $\theta_{\mathrm{CC}}$ em todos os valores de $D s$ abaixo da $D s c$.

Tabela 4. Distribuição estatística da densidade do solo nos tratamentos avaliados.

\begin{tabular}{cccccc}
\hline Tratamento & $\mathrm{N}$ & \multicolumn{3}{c}{$D s^{*}$} \\
\cline { 3 - 6 } & & Média & Desvio Padrão & Mínimo & Máximo \\
\hline CN & 30 & 0,98 & 0,08 & 0,81 & 1,14 \\
Cc & 30 & 1,22 & 0,05 & 1,10 & 1,30 \\
Cs & 30 & 1,22 & 0,06 & 1,12 & 1,35 \\
R2t & 30 & 1,28 & 0,05 & 1,17 & 1,39 \\
R2e & 30 & 1,30 & 0,06 & 1,18 & 1,40 \\
R1t & 30 & 1,34 & 0,06 & 1,20 & 1,44 \\
R1e & 30 & 1,40 & 0,05 & 1,30 & 1,52 \\
\hline *Densidade do solo, $\mathrm{g} \mathrm{cm}^{-3}$ & & & &
\end{tabular}

Nas Figuras 14 a 17 são apresentadas as superfícies de $D s$ correspondentes aos tratamentos sob pastejo rotacionado. Pode-se observar que as limitações causadas por uma $D s$ superior à $D s c$ são mínimas no R2, tanto na posição touceira (Figura 14) quanto na posição entre touceiras (Figura 15). No R1 as restrições por valores de $D s$ superiores à Dsc são observadas na posição touceira (Figura 16), e com maior intensidade na 
posição entre touceiras (Figura 17). No Rle a maior parte da área apresenta valores restritivos ao crescimento de plantas o que pode ser atribuído às maiores taxas de lotação animal empregadas, às quais devem ter sido a causa primária da compactação do solo, conforme discutido em 4.2.



Figura 11 - Superfície de densidade do solo para a área de cerrado $(\mathrm{CN})$.

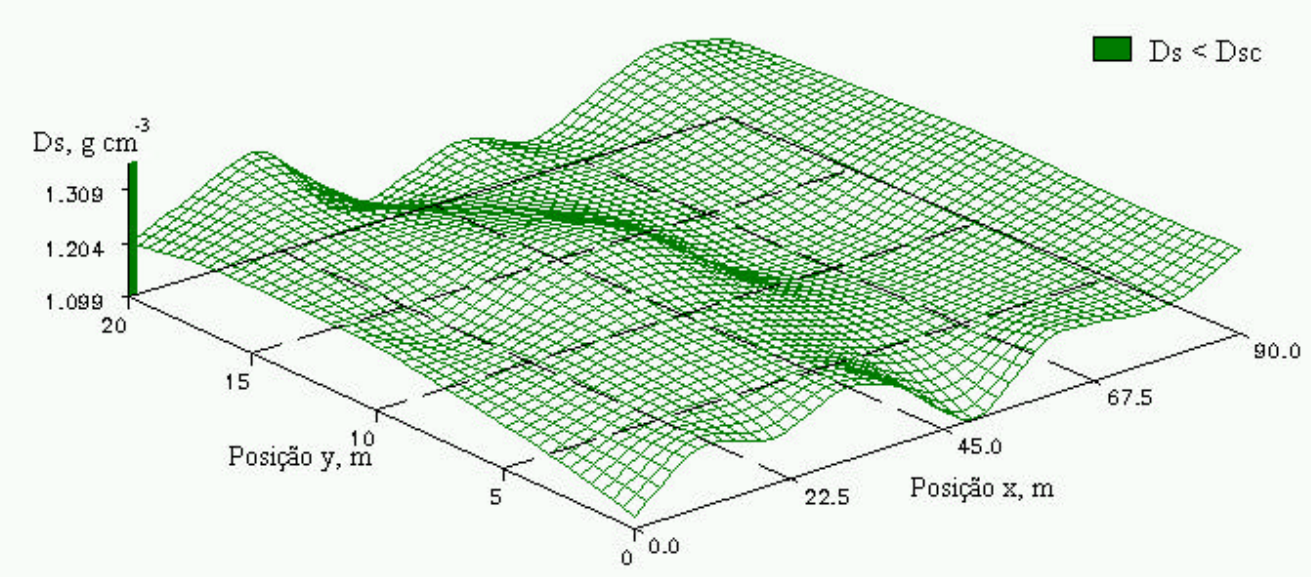

Figura 12 - Superfície de densidade do solo para o sistema de pastejo contínuo com adubação de manutenção (Cc). 


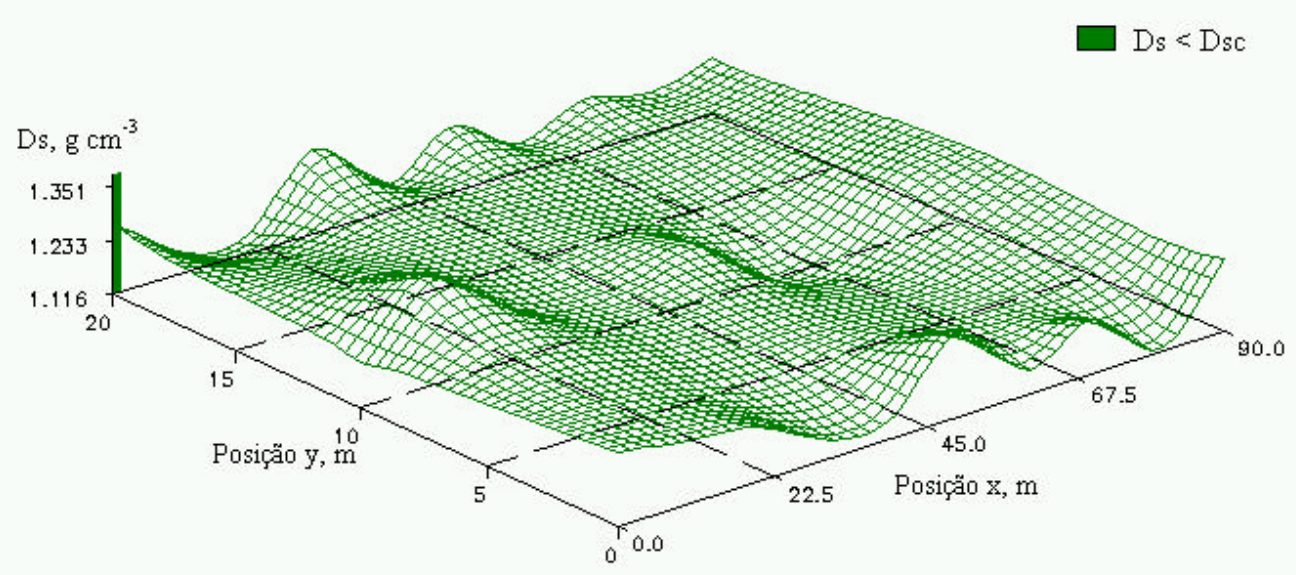

Figura 13 - Superfície de densidade do solo para o sistema de pastejo contínuo sem adubação de manutenção (Cs).

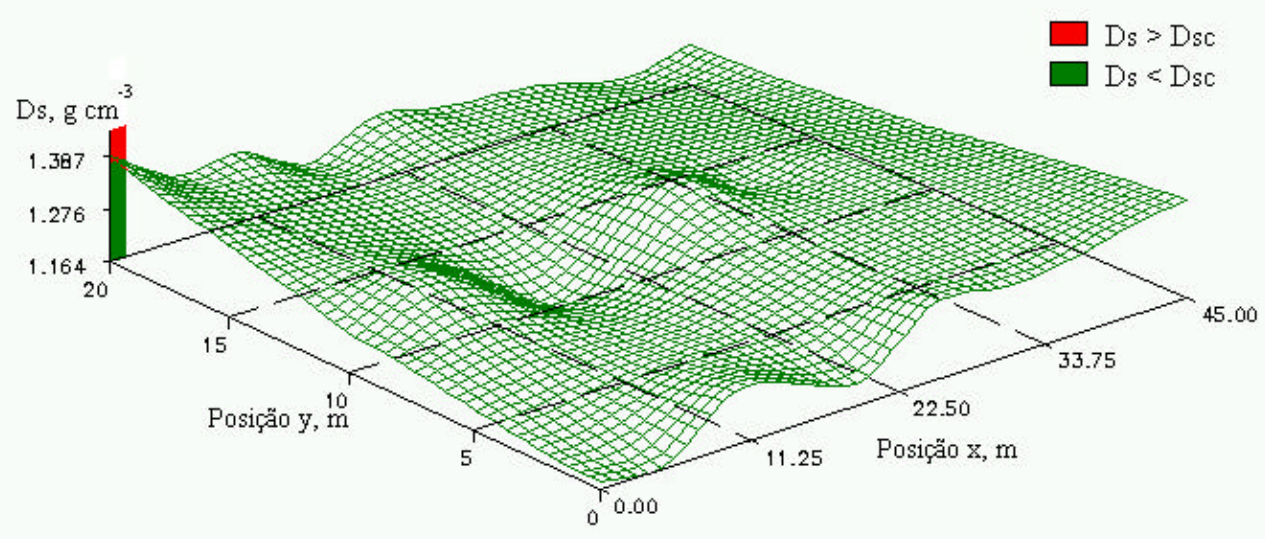

Figura 14 - Superfície de densidade do solo para o sistema de pastejo rotacionado, resíduo pós pastejo de 3,0-3,5 $\mathrm{Mg}$ MST ha-1, considerando amostras retiradas na posição espacial touceira $(\mathrm{R} 2 \mathrm{t})$. 


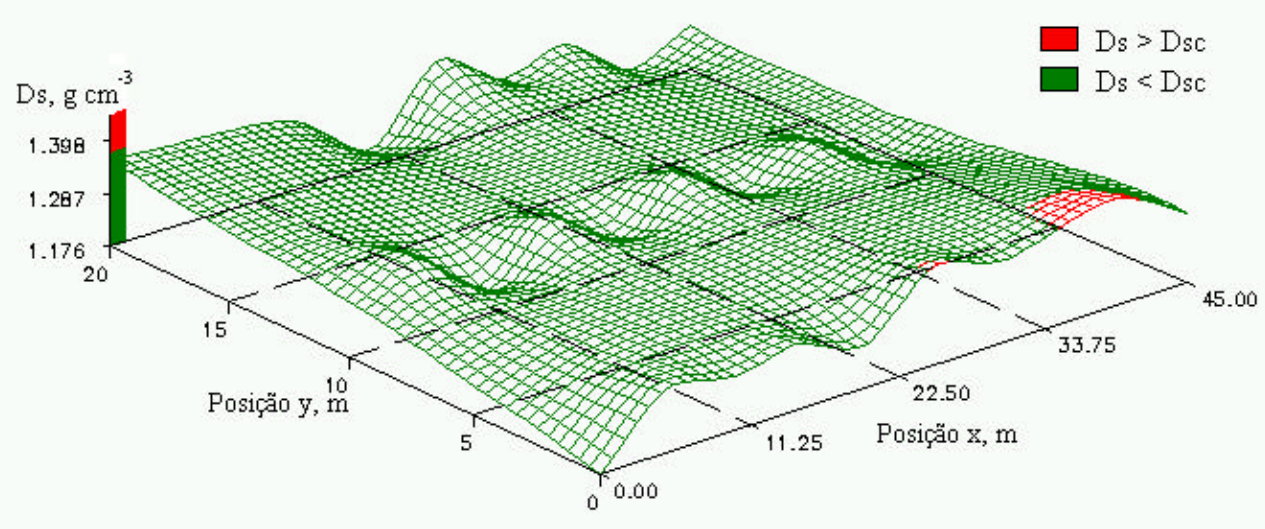

Figura 15 - Superfície de densidade do solo para o sistema de pastejo rotacionado, resíduo pós pastejo de 3,0-3,5 $\mathrm{Mg}$ MST ha ${ }^{-1}$, considerando amostras retiradas na posição espacial entre touceiras $(\mathrm{R} 2 \mathrm{e})$.



Figura 16 - Superfície de densidade do solo para o sistema de pastejo rotacionado, resíduo pós pastejo de 2,0-2,5 $\mathrm{Mg} \mathrm{MST} \mathrm{ha}^{-1}$, considerando amostras retiradas na posição espacial touceira $(\mathrm{R} 1 \mathrm{t})$. 


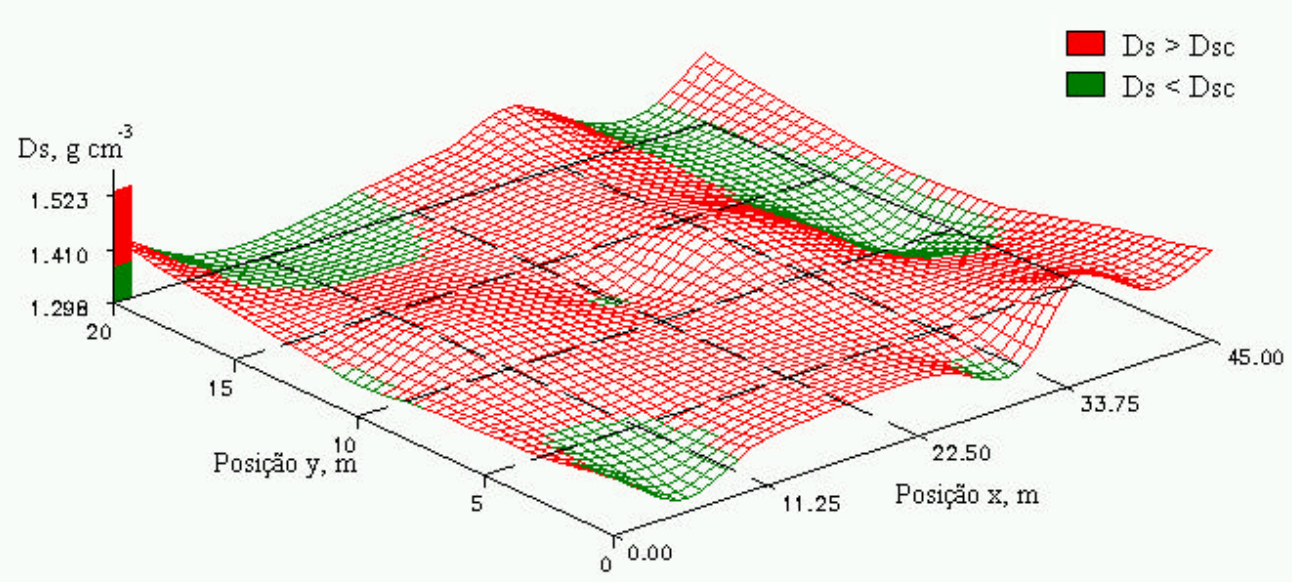

Figura 17 - Superfície de densidade do solo para o sistema de pastejo rotacionado, resíduo pós pastejo de 2,0-2,5 $\mathrm{Mg} \mathrm{MST} \mathrm{ha}^{-1}$, considerando amostras retiradas na posição espacial entre touceiras (R1e). 


\section{CONCLUSÕES}

A conclusão geral deste trabalho foi que o Intervalo Hídrico Ótimo (IHO) foi influenciado pelo uso, sistema de pastejo adotado, e pelo manejo do resíduo pós pastejo utilizado no sistema de pastejo rotacionado, confirmando a hipótese testada. As conclusões específicas foram:

(i) $\mathrm{O}$ IHO foi mais restritivo ao crescimento de plantas no sistema de pastejo rotacionado que no sistema de pastejo contínuo.

(ii) A adubação de manutenção não teve efeito significativo sobre o IHO no sistema de pastejo contínuo estudado, com lotações entre 1,53 e 1,68 $\mathrm{UA} \mathrm{ha}^{-1}$.

(iii) O IHO não foi afetado pela posição espacial (touceira e entre touceiras) no sistema de pastejo rotacionado com resíduo pós pastejo de 3,0-3,5 $\mathrm{Mg} \mathrm{MST} \mathrm{ha}^{-1}$.

(iv) $\mathrm{O}$ IHO foi afetado pela posição espacial (touceira e entre touceiras) no sistema de pastejo rotacionado com resíduo pós pastejo de 2,0-2,5 $\mathrm{Mg} \mathrm{MST} \mathrm{ha}^{-1}$, sendo mais restritivo na posição entre touceiras. 


\section{REFERÊNCIAS BIBLIOGRÁFICAS}

ABAYE, A.O.; ALLEN, V.G.; FONTENOT, J.P. Grazing sheep and cattle together or separately: effect on soil and plants. Agronomy Journal, v.89, p.380-386, 1997.

ALEGRE, J.C.; CASSEL, D.K. Dynamics of soil physical properties under alternative systems to slash-and-burn. Agriculture, Ecosystems and Environment, v.58, p.3948, 1996.

BAVER, L.D.; GARDNER, W.H.; GARDNER, W.R. Soil physics. 4.ed. New York: John Wiley, 1972. 498p.

BELL, M.J.; BRIDGE, B.J.; HARCH, G.R.; ORANGE, D.N. Physical rehabilitation of degraded krasnozems using ley pastures. Australian Journal of Soil Research, v.35, p.1093-1113, 1997.

BENGOUGH, A.G.; McKENZIE, B.M. Simultaneous measurement of root force and elongation for seedling pea roots. Journal of Experimental Botany, v.45, n.270, p.95-102, 1994.

BENGOUGH, A.G.; MULLINS, C.E. Mechanical impedance to root growth: a review of experimental techniques and root growth responses. Journal of soil Science, v.41, p.341-358, 1990.

BETTERIDGE, K.; MACKAY, A.D.; SHEPHERD, T.G.; BARKER, D.J.; BUDDING, P.J.; DEVANTIER, B.P.; COSTALL, D.A. Effect of cattle and sheep treading on surface configuration of a sedimentary hill soil. Australian Journal of Soil Research, v.37, p.743-760, 1999.

BETZ, C.L.; ALLMARAS, R.R.; COPELAND, S.M.; RANDALL, G.W. Least limiting water range: traffic and long-term tillage influences in a Webster soil. Soil Science Society of America Journal, v.62, p.1384-1393, 1998. 
BLAKE, G.R.; HARTGE, K.H. Bulk density. In: KLUTE, A. (Ed.). Methods of soil analysis: physical and mineralogical methods. 2.ed. Madison: American Society of Agronomy, 1986. cap.13, p.363-375.

BOUMA, J. Using soil survey data for quantitative land evaluation. Advances in Soil Science, v.9, p.177-213, 1989.

BRADFORD, J.M. The penetration resistance in a soil with well-defined structural units. Soil Science Society of America Journal, v.44, p.601-606, 1980.

BRADFORD, J.M. Penetrability. In: KLUTE, A. (Ed.). Methods of soil analysis: physical and mineralogical methods. 2.ed. Madison: American Society of Agronomy, 1986. cap.11, p.463-478.

BRADY, N. C.; WEIL, R. R. The nature and properties of soils. 12.ed. New Jersey: Prentice Hall, 1999. 881p.

BUSSCHER, W.J. Adjustment of flat-tipped penetrometer resistance data to a common water content. Transactions of ASAE, v.33, n.2, p.519-524, 1990.

CAMP, C.R.; GILL, W.R. The effect of drying on soil strength parameters. Soil Science Society of America Proceedings, v.33, p.641-644, 1969.

CARTER, M.R.; ANGERS, D.A.; TOPP, G.C. Characterizing equilibrium physical condition near the surface of a fine sandy loam under conservation tillage in a humid climate. Soil Science, v.164, n.2, p.101-110, 1999.

CHANASYK, D.S.; NAETH, M.A. Grazing impacts on bulk density as soil strength in the foothills fescue grasslands of Alberta, Canada. Canadian Journal of Soil Science, v.75, p.551-557, 1995.

CORREA, J.C.; REICHARDT, K. Efeito do tempo de uso das pastagens sobre as propriedades de um Latossolo Amarelo da Amazônia Central. Pesquisa Agropecuária Brasileira, v.30, n.1, p.107-114, 1995.

CORRECHEL, V. Densidade do solo: influência da posição relativa à linha de plantio em dois sistemas de preparo do solo. Piracicaba, 1998. 41p. Dissertação (Mestrado) - Escola Superior de Agricultura "Luiz de Queiroz", Universidade de São Paulo. 
DAVIES, A.; ADAMS, W.A.; WILMAN, D. Soil compaction in permanent pasture and its amelioration by slitting. Journal of Agricultural Science, v.113, p.189-197, 1989.

DECAËNS, T.; JIMÉNEZ, J.J.; LAVELLE, P. Effect of exclusion of the anecic earthworm Martiodrilus carimaguensis Jiménez and Moreno on soil properties and plant growth in grasslands of the eastern plains of Colombia. Pedobiologia, v.43, p.835-841, 1999.

DEXTER, A.R. Advances in characterization of soil structure. Soil and Tillage Research, v.11, p.199-238, 1988.

DEXTER, A.R.; BIRD, N.R.A. Methods for predicting the optimum and the range of soil water contents for tillage based on the water retention curve. Soil and Tillage Research, v.57, p.203-212, 2001.

EARL, R. Prediction of trafficability and workability from soil moisture deficit. Soil and Tillage Research, v.40, p.155-168, 1997.

EAVIS, B.W. Soil physical conditions affecting seedling root growth: I. Mechanical impedance, aeration and moisture availability as influenced by bulk density and moisture level in a sandy loam soil. Plant and Soil, v.36, p.613-622, 1972.

EMPRESA BRASILEIRA DE PESQUISA AGROPECUÁRIA. Serviço Nacional de Levantamento e Conservação de Solos. Levantamento de reconhecimentodetalhado e aptidão agrícola dos solos da área do Centro Nacional de Pesquisa de Gado de Corte, Mato Grosso do Sul. Rio de Janeiro: Embrapa/SNLCS. 1979. $255 \mathrm{p}$.

EMPRESA BRASILEIRA DE PESQUISA AGROPECUÁRIA. Centro Nacional de Pesquisa de Solos. Sistema Brasileiro de Classificação de Solos. Brasília: Embrapa Produção de Informação, 1999. 412p.

FRANCIS, G.S.; TABLEY, F.J.; WHITE, K.M. Restorative crops for the amelioration of degraded soil conditions in New Zealand. Australian Journal of Soil Research, v.37, p.1017-1034, 1999. 
GARDNER, W.H. Water content. In: KLUTE, A. (Ed.). Methods of soil analysis: physical and mineralogical methods. 2.ed. Madison: American Society of Agronomy, 1986. cap.21, p.493-544.

GEE, G.W.; BAUDER, J.W. Particle-size analysis. In: KLUTE, A. (Ed.). Methods of soil analysis: physical and mineralogical methods. 2.ed. Madison: American Society of Agronomy, 1986. cap.15, p.383-409.

GLANTZ, S.A.; SLINKER, B.K. Primer of applied regression and analysis of variance. New York: McGraw-Hill, 1990. 770p.

GRABLE, A.R.; SIEMER, E.G. Effects of bulk density, aggregate size, and soil water suction on oxygen diffusion, redox potential and elongation of corn roots. Soil Science Society of America Journal, v. 32, n.2, p.180-186, 1968.

GROENEVELT, P.H.; GRANT, C.D.; SEMETSA, S. A new procedure to determine soil water availability. Australian Journal of Soil Research, v.39, p.577-598, 2001.

HAISE, H.R.; HAAS, H.J.; JENSEN, L.R. Soil moisture studies of some great plains soils. II. Field capacity as related to $1 / 3$-atmosphere percentage, and minimum point as related to 15- and 26-atmosphere percentage. Soil Science Society of America Proceedings, v.34, p.20-25, 1955.

HALL, D.J.M.; McKENZIE, D.C.; MACLEOD, D.A.; BARRET, A. Amelioration of a hardsetting Alfisol through deep mouldboard ploughing, gypsum application and double cropping. I. Soil physical and chemical properties. Soil and Tillage Research, v.28, p.253-270, 1994.

HARRISON, D.F.; CAMERON, K.C.; McLAREN, R.G. Effects of subsoil loosening on soil physical properties, plant root growth, and pasture yield. New Zealand Journal of Agricultural Research, v.37, p.559-567, 1994.

HART, P.B.S.; AUGUST, J.A.; ROSS, C.W. Some biochemical and physical properties of Tokomaru silt loam under pasture and after 10 years of cereal cropping. New Zealand Journal of Agricultural Research, v.31, p.77-86, 1988. 
HERRICK, J.E.; JONES, T.L. A dynamic cone penetrometer for measuring soil penetration resistance. Soil Science Society of America Journal, v.66, p.13201324, 2002.

HOOK, P.B.; BURKE, I.C.; LAUENROTH, W.K. Heterogeneity of soil and plant N and $\mathrm{C}$ associated with individual plants and openings in North American shortgrass steppe. Plant and Soil, v.138, n.1, p.247-256, 1991.

HURLEY, M.B.; ROWARTH, J.S. Resistance to root growth and changes in the concentrations of ABA within the root and xylem sap during root-restriction stress. Journal of Experimental Botany, v.50, n.335, p.799-804, 1999.

IMHOFF, S. Indicadores de qualidade estrutural e trafegabilidade de latossolos e argissolos vermelhos. Piracicaba, 2002. 94p. Tese (Doutorado) - Escola Superior de Agricultura "Luiz de Queiroz", Universidade de São Paulo.

IMHOFF, S.; SILVA, A.P.; TORMENA, C.A. Spatial heterogeneity of soil properties in areas under elephant-grass short-duration grazing system. Plant and Soil, v.219, p.161-168, 2000a.

IMHOFF, S.; SILVA, A.P.; TORMENA, C.A. Aplicações da curva de resistência no controle da qualidade física de um solo sob pastagem. Pesquisa Agropecuária Brasileira, v.35, n.7, p.1493-1500, 2000b.

IMHOFF, S.; SILVA, A.P.; DIAS JUNIOR, M.S.; TORMENA, C.A. Quantificação das pressões críticas para o crescimento das plantas. Revista Brasileira de Ciência do Solo, v.25, p.11-18, 2001.

ISMAIL, M.R.; DAVIES, W.J. Root restriction affects leaf growth and stomatal response: the role of xylem sap ABA. Scientia Horticulturae, v.74, p.257-268, 1998.

KERTZMAN, F.F. Modificações na estrutura e no comportamento de um Latossolo Roxo provocadas pela compactação do solo. São Paulo, 1996. 176p. Tese (Doutorado) - Faculdade de Filosofia, Letras e Ciências Humanas, Universidade de São Paulo. 
KLUTE, A. Water retention: laboratory methods. In: KLUTE, A. (Ed.). Methods of soil analysis: physical and mineralogical methods. 2.ed. Madison: American Society of Agronomy, 1986. cap.26, p.635-660.

KRZIC, M.; NEWMAN, R.F.; BROERSMA, K.; BOMKE, A.A. Soil compaction of forest plantations in interior British Columbia. Journal of Range Management, v.52, p.671-677. 1999.

LAL, R. Physical management of soils of the tropics: priorities for the $21^{\text {st }}$ century. Soil Science, v.135, n.3, p.191-207. 2000.

LETEY, J. Relationship between soil physical properties and crop production. Advances in Soil Science, v.1, p.277-294, 1985.

LIBARDI, P.L. Dinâmica da água no solo. 2.ed. Piracicaba: ESALQ, Departamento de Ciências Exatas, 2000. 509p.

MACEDO, M.C.M. Integração lavoura e pecuária: alternativa para sustentabilidade da produção animal. In: MOURA, J.C.; SILVA, S.C.; FARIA, V.P. (Ed.). PLANEJAMENTO DE SISTEMAS DE PRODUÇÃO EM PASTAGENS, Piracicaba, 2001, Anais. Piracicaba: FEALQ, 2001. p. 257-283.

MAPFUMO, E.; CHANASYK, D.S.; BARON, V.S.; NAETH, M.A. Grazing impacts on selected soil parameters under short-term forage sequences. Journal of Range Management, v.53, p.466-470, 2000.

MAPFUMO, E.; CHANASYK, D.S.; NAETH, M.A. BARON, V.S. Forage growth and yield components as influenced by subsurface compaction. Agronomy Journal, v.90, p.805-812, 1998.

MATERECHERA, S.A.; DEXTER, A.R.; ALSTON, A.M. Penetration of very strong soils by seeding of different plant species. Plant and Soil, v.135, n.1, p.31-41, 1991.

MAZZA, J.A.; VITTI, G.C.; PEREIRA, H.S.; MENEZES, G.M.; TAGLIARINI, C.H. Influência da compactação no desenvolvimento do sistema radicular de citros: sugestão de método qualitativo de avaliação e recomendação de manejo. Laranja, v.15, n.2, p.251-262, 1994. 
McKENZIE, D.C.; McBRATNEY, A.B. Cotton root growth in a compacted Vertisol (Grey Vertosol): I. Predictions using strength measurements and limiting water ranges. Australian Journal of Soil Research, v.39, p.1157-1168, 2001.

MEAD, J.A.; CHAN, K.Y. Cultivation techniques and grazing affect surface structure of an Australian hardsetting soil. Soil and Tillage Research, v.25, p.217-230, 1992.

MENGEL, K.; KIRKBY, E.A. Principles of plant nutrition. 3.ed. Worblaufen: International Potash Institute, 1982. 655p.

MEROTTO, A.; MUNDSTOCK, C.M. Wheat root growth as affected by soil strength. Revista Brasileira de Ciência do Solo, v.23, p.197-202, 1999.

MÜLLER, L.; TILLE, P.; KRETSCHMER, H. Trafficability and workability of alluvial clay soils in response to drainage status. Soil and Tillage Research, v.16, p.237287, 1990.

MULlER, M.M.L.; GUIMARÃES, M. F.; DESJARDINS, T.; MARTINS, P.F.S. Degradação de pastagens na Região Amazônica: propriedades físicas do solo e crescimento de raízes. Pesquisa Agropecuária Brasileira, v.36, n.11, p.1409-1418, 2001.

NELSON, W.L., MEHLICH, A., WINTERS, E. The development evaluation and use of soil tests for phosphorus availability. In: PIERRE, W.H.; NORMAN, A.G. (Ed.). Soil fertilizer phosphorus in crop nutrition. New York: Academic Press, 1953. cap.6, p.153-188.

NETER, J.; WASSERMAN, W.; KUTNER, M.H. Applied linear regression models. 2.ed. Homewood: Irwin, 1989. 667p.

NIE, Z.N.; WARD, G.N.; MICHAEL, A.T. Impact of pugging by dairy cows on pastures and indicators of pugging damage to pasture soil in south-western Victoria. Australian Journal of Agricultural Research, v.52, p.37-43, 2001.

PABIN, J.; LIPIEC, J.; W£ODEK, S.; BISKUPSKI, A.; KAUS, A. Critical soil bulk density and strength for pea seedling growth as related to other soil factors. Soil and Tillage Research, v.46, p.203-208, 1998.

PASSIOURA, J.B. Soil structure and plant growth. Australian Journal of Soil Research, v.29, p.717-728, 1991. 
PHENE, C.J.; BEALE, W. High-frequency irrigation for water nutrient management in humid regions. Soil Science Society of America Journal, v.40, p.430-436, 1976. PIVELLO, V.R.; COUTINHO, L.M. A qualitative successional model to assist in the management of the Brazilian cerrados. Forest Ecology and Management, v.87, p.127-138, 1996.

PROFFITT, A.P.B.; BENDOTTI, S.; RIETHMULLER, G.P. A comparison between continuous and controlled grazing on a red duplex soil. I. Effects on soil physical characteristics. Soil and Tillage Research, v.35, p.199-210, 1995 b.

PROFFITT, A.P.B.; BENDOTTI, S.; RIETHMULLER, G.P. A comparison between continuous and controlled grazing on a red duplex soil. II. Subsequent effects on seedbed conditions, crop establishment and growth. Soil and Tillage Research, v.35, p.211-225, 1995a.

RATKOWSKY, D.A. Handbook of nonlinear regression models. New York:Marcel Dekker, 1990. 241p.

REICHARDT, K. Capacidade de campo. Revista Brasileira de Ciência do Solo, v.12, n.3, p.211-216, 1988.

REICHARDT, K. Dinâmica da matéria e da energia em ecossistemas. 2.ed. Piracicaba: ESALQ, Departamento de Física e Meteorologia, 1996. 505p.

RICHARDS, L.A.; WEAVER, L.R. Fifteen atmosphere percentage as related to the permanent wilting point. Soil Science, v.56, p.331-339, 1944.

SANCHEZ, P. Properties and management of soils in the tropics. New York: John Wiley, 1976. 618p.

SANDS, R,; GREACEN, E.L.; GERARD, C.J. Compaction of sandy soils in radiata pine forests: I. A penetrometer study. Australian Journal of Soil Research, v.17, p.101-113, 1979.

SAS INSTITUTE INCORPORATION. SAS ${ }^{\text {() }}$ System for regression. 2.ed. Cary, NC: SAS Institute, 1991. 210p.

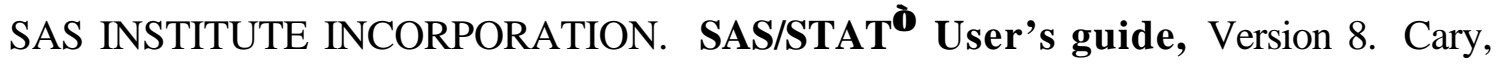
NC: SAS Institute, 1999. p.25-50. 
SAS INSTITUTE INCORPORATION. SAS/GRAPH ${ }^{\circledR}$ Software: Reference, Version 8. Cary, NC: SAS Institute, 2000. 2v. 1272p.

SCHOENHOLTZ, S.H.; VAN MIEGROET, H.; BURGER, J.A. A review of chemical and physical properties as indicators of forest soil quality: challenges and opportunities. Forest Ecology and Management, v.138, p.335-356, 2000.

SHARMA, P.K.; BHUSHAN, L. Physical characterization of a soil amended with organic residues in a rice-wheat cropping system using a single value soil physical index. Soil and Tillage Research, v.60, p.143-152, 2001.

SILVA, A.P.; KAY, B.D. The sensitivity of shoot growth of corn to the least limiting water range of soils. Plant and Soil, v.184, p.323-329, 1996.

SILVA, A.P.; KAY, B.D. Estimating the least limiting water range of soils from properties and management. Soil Science Society of America Journal, v.61, p.877883, 1997a.

SILVA, A.P.; KAY, B.D. Effect of soil water content variation on the least limiting water range. Soil Science Society of America Journal, v.61, p.884-888, 1997b.

SILVA, A.P.; KAY, B.D.; PERFECT, E. Characterization of the least limiting water range of soils. Soil Science Society of America Journal, v.58, p.1775-1781, 1994.

SILVA, A.P.; KAY, B.D.; PERFECT, E. Management versus inherent soil properties effects on bulk density and relative compaction. Soil and Tillage Research, v.44. p.81-93, 1997b.

SILVA, A.P.; TORMENA, C.A.; MAZZA, J.A. Manejo físico de solos sob pastagem. In: PEIXOTO, A.M.; MOURA, J.C.; FARIA, V.P. (Ed.). FUNDAMENTOS DO PASTEJO ROTACIONADO, Piracicaba, 1997, Anais. Piracicaba: FEALQ, 1997a. p.25-35.

SILVA, A.P.; IMHOFF, S.C.; TORMENA, C.A.; LEÃO, T.P. Avaliação da compactação de solos florestais. In: GONÇALVES, J.L.M.; STAPE, J.L. (Ed.). Conservação e cultivo de solos para plantações florestais. Piracicaba: IPEF, 2002a. cap.10, p.351-372. 
SILVA, A.P.; IMHOFF, S.; TORMENA, C.A.; LIMA, C.R.; TAKAHAMA, R.S. Qualidade física de solos sob sistemas intensivos de pastejo rotacionado. In: PEIXOTO, A.M.; MOURA, J.C.; PEDREIRA, C.G.S.; FARIA, V.P. (Ed.). INOVAÇÕES TECNOLÓGICAS NO MANEJO DE PASTAGENS, Piracicaba, 2002b, Anais. Piracicaba: FEALQ, 2002. p. 79-97.

SOJKA, R.E.; BUSSCHER, W.J.; LEHRSCH, G.A. In situ strength, bulk density, and water content relations of a durinodic xeric haplocalcid soil. Soil Science, v.166, n.8, p.520-529, 2001.

SOUZA, A.J. Preparo de solos coesos para cultura do eucalipto no extremo sul da Bahia. In: GONÇALVES, J.L.M.; STAPE, J.L. (Ed.). Conservação e cultivo de solos para plantações florestais. Piracicaba: IPEF, 2002. cap.8, p.297-311.

STEPHENSON, G.R.; VEIGEL, A. Recovery of compacted soil on pastures used for winter cattle feeding. Journal of Range Management, v.40, n.1, p. 46-48, 1987.

STOLF, R. Teoria e teste experimental de fórmulas de transformação dos dados de penetrômetro de impacto em resistência do solo. Revista Brasileira de Ciência do Solo, v.15, p.229-235, 1991.

TANNER, C.B.; MAMARIL, C.P. Pasture compaction by animal traffic. Agronomy Journal, v.51, n.6, p.329-331, 1959.

TAYLOR, H.M.; ROBERSON, G.M.; PARKER, J.J. Soil strength-root penetration relations to coarse textured materials. Soil Science, v.102, n.1, p.18-22, 1966.

TENGE, A.J.; KAIHURAA, F.B.S.; LAL, R.; SINGH, B.R. Diurnal soil temperature fluctuations for different erosion classes of na oxisol at Mlingano, Tanzania. Soil and Tillage Research, v.49, p.211-217, 1998.

TOPP, G.C.; ZEBCHUK, W. The determination of soil water desorption curves for soil cores. Canadian Journal of Soil Science, v.59, p.19-26, 1979.

TORMENA, C.A. Caracterização e avaliação do intervalo hídrico ótimo de um Latossolo Roxo. Piracicaba, 1998. 106p. Tese (Doutorado) - Escola Superior de Agricultura “Luiz de Queiroz”, Universidade de São Paulo. 
TORMENA, C.A.; SILVA, A.P.; LIBARDI, P.L. Caracterização do intervalo hídrico ótimo de um Latossolo Roxo sob plantio direto. Revista Brasileira de Ciência do Solo, v.22, p.573-581, 1998.

TORMENA, C.A.; SILVA, A.P.; LIBARDI, P.L. Soil physical quality of a Brazilian Oxisol under two tillage systems using the least limiting water range approach. Soil and Tillage Research, v.52, p.223-232, 1999.

TRIMBLE, S.W.; MENDEL, A.C. The cow as a geomorphic agent - A critical review. Geomorphology, v.13, p.233-253, 1995.

VAN DEN BERG, M.; KLAMT, E.; VAN REEUWIJK, L.P.; SOMBROEK, W.G. Pedotransfer functions for the estimation of moisture retention characteristics of Ferralsols and related soils. Geoderma, v.78, p.161-180, 1997.

VAN HAVEREN, B.P. Soil bulk density as influenced by grazing intensity and soil type on a shortgrass praire site. Journal of Range Management, v.35, n.5, p.586588, 1983.

WARREN, S.D.; NEVILL, M.B.; BLACKBURN, W.H.; GARZA, N.E. Soil response to trampling under intensive rotation grazing. Soil Science Society of America Journal, v.50, p.1336-1341, 1986.

WEAICH, K.; CASS, A.; BRISTOW, K.L. Pre-emergent shoot growth of maize Zea mays L.) as a function of soil strength. Soil and Tillage Research, v.40, p.3-23, 1996.

WILLIAMS, M.J.; KALMBACHER, R.S. Renovation effects on bahiagrass productivity. Agronomy Journal, v.88, p.191-198, 1996.

ZOU, C.; SANDS, R.; BUCHAN, G.; HUDSON, I. Least limiting water range: a potential indicator of physical quality of forest soils. Australian Journal of Soil Research, v.38, p.947-958, 2000. 